\title{
Identification of Two Protein Kinases That Phosphorylate the Neural Cell-Adhesion Molecule, N-CAM
}

\author{
Ken Mackie, ${ }^{1}$ Barbara C. Sorkin, ${ }^{2}$ Angus C. Nairn, ${ }^{1}$ Paul Greengard, ${ }^{1}$ Gerald M. Edelman, ${ }^{2}$ and Bruce A. \\ Cunningham ${ }^{2}$ \\ 'Laboratory of Molecular and Cellular Neuroscience and 'Laboratory of Developmental and Molecular Biology, The \\ Rockefeller University, New York, New York 10021
}

The neural cell-adhesion molecule (N-CAM) is detected as at least 3 related polypeptides generated by alternative splicing of a single gene. In vivo the 2 larger polypeptides are phosphorylated, but the smallest polypeptide, which lacks a cytoplasmic domain, is not. We have found that the 2 larger polypeptides are phosphorylated in vivo on several common phosphorylation sites. Furthermore, the largest polypeptide has additional sites, suggesting that some phosphorylation occurs in that portion of the intracellular region unique to it. In vitro N-CAM is not a substrate for cyclic AMP-dependent protein kinase, cyclic GMP-dependent protein kinase, calcium/calmodulin-dependent protein kinase I, II, or III, protein kinase $\mathrm{C}$, or casein kinase II. However, we have isolated 2 protein kinases from mammalian and avian brain that phosphorylate rodent and chicken N-CAM. On the basis of their chromatographic behavior and substrate specificity, the 2 kinases are glycogen synthase kinase 3 (GSK-3) and casein kinase I (CK I). The 2 kinases phosphorylate $\mathrm{N}$-CAM rapldly, to a high stoichiometry and with a low $K_{m}$ for N-CAM, suggesting that the phosphorylation of N-CAM by these kinases is physiologically relevant. Both enzymes phosphorylate the 2 larger N-CAM polypeptides in vitro in the cytoplasmic domain on threonyl residues that are phosphorylated to a low level in vivo. In addition, the threonyl residues are close to seryl residues phosphorylated to a high level in vivo. Prior phosphorylation at the in vivo sites appears to be a prerequisite for phosphorylation by GSK-3 and CK I. Taken together, the results suggest that N-CAM may be physiologically phosphorylated on 2 sets of interrelated sites, one demonstrable in vivo and one in vitro. Phosphorylation on the "in vivo" sites is resistant to dephosphorylation and may be constitutive, while phosphorylation on the "in vitro" sites is much more labile.

The neural cell adhesion molecule, N-CAM, mediates cell-cell interactions throughout development and in the adult. Alterations in levels of N-CAM expression play critical roles at sites of embryonic induction (Thiery et al., 1982; Edelman, 1984, 1985). N-CAM isolated from chicken or rodent brain contains at least 3 major polypeptides with $M$, values of $160,000,130,000$,

\footnotetext{
Received Oct. 9, 1987; revised Nov. 15, 1988; accepted Nov. 21, 1988.

This work was supported by a Senator Jacob Javits Center for Fxcellence in Neuroscience Award NS-22789 and by Environmental Protection Agency Contract CR-813826-01-0.

Correspondence should be addressed to Angus C. Nairn, Box 296, The Rockefeller University, 1230 York Avenue, New York, NY 10021.

Copyright (C) 1989 Society for Neuroscience $0270-6474 / 89 / 061883-14 \$ 02.00 / 0$
}

and 110,000, which have been designated the ld, sd, and ssd polypeptides, respectively (Cunningham et al., 1983; Hemperly et al., 1986b). The 3 polypeptides are generated by alternative splicing of a single gene in chicken (Murray et al., 1986a; Cunningham et al., 1987) and in mouse (Gennarini et al., 1986; Barbas et al., 1988) and differ primarily in their association with the membrane and in their cytoplasmic domains. The ssd polypeptide lacks a cytoplasmic domain (Hemperly et al., 1986b). The ld polypeptide differs from the sd polypeptide by the presence of 261 additional amino acids, which constitute the bulk of its intracellular domain (Hcmperly ct al., 1986a; Murray ct al., 1986b).

Both the Id and sd polypeptides are phosphorylated in vivo (Hoffman et al., 1982; Gennarini et al., 1984; Lyles et al., 1984; Sorkin et al., 1984); ssd is not phosphorylated on amino acids (Gennarini et al., 1984). Phosphorylation occurs on both seryl and threonyl residues in chicken N-CAM (Sorkin et al., 1984) and has been reported to occur only on seryl residues in mouse N-CAM (Gennarini et al., 1984). Phosphotyrosine has never been detected. The ratios of ${ }^{32} \mathrm{P}-\mathrm{Ser}$ to ${ }^{32} \mathrm{P}-\mathrm{Thr}$ are different in the 2 chicken polypeptides, and there is greater incorporation of ${ }^{32} \mathrm{PO}_{4}$ per mole into the ld species (Sorkin et al., 1984), raising the possibility that some, but not all, of the phosphorylation occurs in the additional cytoplasmic sequence.

Protein phosphorylation is an important mechanism for the regulation of protein function in many systems (Nestler and Greengard, 1984; Greengard, 1987) and as such may influcnce the activity of N-CAM. In particular, it may alter its surface density, binding characteristics, or interactions with other molecules at the cell surface, in the cytoskeleton or in the cytoplasm. In the current study we have further characterized the phosphorylation sites in N-CAM with respect to their locations within the ld and sd polypeptides and have shown that N-CAM is phosphorylated in vitro by 2 "independent" protein kinases, the kinetic properties of each being typical of physiological phosphorylation reactions. Our results also suggest that N-CAM contains 2 types of phosphorylation sites, one of which is much more resistant to dephosphorylation, and that these 2 types of phosphorylation sites may interact with each other.

\section{Materials and Methods}

Materials. Chicken, mouse, and rat N-CAM were prepared as previously described (Chuong et al., 1982; Hoffman et al., 1982). Protein phosphatase $2 \mathrm{~A}$, purified by the method of Resink et al. (1983), was the gift of Dr. H. C. Hemmings, Jr. Protein kinase C, purified by a modification of the method of Kikkawa et al. (1982), was the gift of Dr. K. Albert. Calcium/calmodulin-dependent protein kinase II, purified by the meth- 
od of McGuinness et al. (1985), was the gift of Dr. Y. Lai. Rabbit skeletal muscle glycogen synthase kinase-3 (GSK-3) purified by the method of Woodgett and Cohen (1984) was the gift of Dr. P. Cohen. The following proteins and enzymes were prepared by published procedures: protein phosphatase inhibitor-2 (Foulkes and Cohen, 1980), type II regulatory and catalytic subunits of cyclic AMP-dependent protein kinase (Kaczmarek et al., 1980), cyclic GMP-dependent protein kinase (Walter et al., 1980), calcium/calmodulin-dependent protein kinase I (Nairn and Greengard, 1987), calcium/calmodulin-dependent protein kinase III (Nairn et al., 1985), and calmodulin (Grand et al., 1979). Casein kinase I and II were prepared as described (Hathaway and Traugh, 1983; Hathaway ct al., 1983) through the hydroxylapatite step. Casein kinase II was further chromatographed on an Ultrogel AcA44 gel-filtration column to remove contaminating casein kinase I activity.

$\gamma-{ }^{32} \mathrm{P}-\mathrm{ATP},{ }^{32} \mathrm{P}$-orthophosphoric acid, and ${ }^{25}$ I-protein A were from New England Nuclear. Diethylaminoethyl cellulose (DE-52) was from Whatman. P-23 phosphocellulose was from Serva. Ultrogel AcA44 was from LKB. Affigel blue and HTP hydroxylapatite were from Biorad. Chymotrypsin and thermolysin were from Worthington. Trypsin and potato acid phosphatase were from Sigma. Neuraminidase was from Calbiochem. Bacterial alkaline phosphatase was from Cooper Biomedical. Phosphate-free minimum essential medium (MEM) was from Flow Laboratories.

Buffers. Buffer A consisted of $25 \mathrm{~mm}$ Tris ( $\mathrm{pH} 7.4), 1 \mathrm{~mm}$ ethylenediamine tetraacetate (EDTA), $15 \mathrm{~mm} \beta$-mercaptoethanol, $5 \%$ (vol/vol) glycerol. Buffer B consistcd of $20 \mathrm{~mm}$ Tris (pH 7.4), $1 \mathrm{~mm}$ EDT, 300 $\mathrm{mm} \mathrm{NaCl}, 15 \mathrm{~mm} \beta$-mercaptoethanol, $15 \%$ (vol/vol) ethylene glycol and $0.02 \%$ sodium azide. Buffer $C$ consisted of $25 \mathrm{~mm}$ Tris ( $\mathrm{pH} 7.5), 1 \mathrm{~mm}$ EDTA, $15 \mathrm{~mm} \beta$-mercaptoethanol, and $50 \%$ (vol/vol) ethylene glycol. Buffer D consisted of $25 \mathrm{~mm}$ Tris ( $\mathrm{pH} 7.5), 200 \mathrm{~mm} \mathrm{NaCl}, 5 \mathrm{~mm}$ EDTA, $1 \% \mathrm{NP}-40,100 \mathrm{~mm} \mathrm{NaF}, 20 \mathrm{~mm}$ sodium pyrophosphate, $10 \mu \mathrm{g} / \mathrm{ml}$ leupeptin, $10 \mu \mathrm{g} / \mathrm{ml}$ pepstatin $\mathrm{A}$, and $200 \mathrm{U} / \mathrm{ml}$ Trasylol. The $\mathrm{pH}$ values for these buffers refer to measurements made at $4^{\circ} \mathrm{C}$.

$N-C A M$ phosphorylation assays. Purified embryonic chicken N-CAM in solution, or bound to monoclonal anti-N-CAM coupled to Sepharose CL-2B, was used as substrate, with identical results. N-CAM was present in the assay in concentrations ranging from 0.5 to $350 \mu \mathrm{g} / \mathrm{ml}$. The reaction volume was typically $100 \mu \mathrm{l}$. Calcium/calmodulin-dependent phosphorylation of N-CAM was assayed in a reaction mixture containing $50 \mathrm{~mm}$ Tris ( $\mathrm{pH} 8.0$ ), $5 \mathrm{~mm} \mathrm{MgCl}_{2}, 0.5 \mathrm{~mm}$ EDTA, $0.5 \mathrm{~mm}$ ethyleneglycol-bis-( $\beta$-aminoethylether)N,N'-tetraacetate (EGTA), $1 \mathrm{~mm}$ dithioerythritol, $1.5 \mathrm{mM} \mathrm{CaCl}_{2}, 0.03 \mu \mathrm{g} / \mathrm{ml}$ calmodulin, $50 \mu \mathrm{M} \gamma-{ }^{32} \mathrm{P}$-ATP (500-1500 $\mathrm{cpm} / \mathrm{pmol}$, and $0.2-0.5 \mu \mathrm{g} / \mathrm{ml}$ of calcium/calmodulin-dependent protein kinase I, II, or III. Phosphorylation of N-CAM by protein kinase $C$ was assayed with the reaction mixture described by Walaas et al. (1983), using $0.2 \mu \mathrm{g} / \mathrm{ml}$ protein kinase C. Phosphorylation of N-CAM by casein kinase I and II, GSK-3, the catalytic subunit of cyclic AMP-dependent protein kinase and cyclic GMP-dependent protein kinase was measured in a reaction mixture containing 50 mм HEPES $\left(N\right.$-2-hydroxyethylpiperazine- $N^{\prime}$-2-ethanesulfonate; $\left.\mathrm{pH} 7.4\right), 10 \mathrm{~mm}$ $\mathrm{MgSO}_{4}, 1 \mathrm{~mm}$ EDTA, $1 \mathrm{~mm}$ EGTA, and $50 \mu \mathrm{M} \gamma$-32P-ATP (500-1500 $\mathrm{cpm} / \mathrm{pmol}$; standard reaction mixture). Cyclic GMP $(10 \mu \mathrm{M})$ was present in assays using cyclic GMP-dependent protein kinase. Varying concentrations of casein kinase I and II and GSK-3 were used depending on the experiment. The concentrations of the catalytic subunit of cyclic AMP-dependent protein kinase and of cyclic GMP-dependent protein kinase were 3 and $1 \mu \mathrm{g} / \mathrm{ml}$, respectively.

The assays were initiated by the addition of $\gamma^{32} \mathrm{P}-\mathrm{ATP}$, and the samples were incubated at $30^{\circ} \mathrm{C}$ for $5 \mathrm{~min}$, unless otherwise indicated. In those assays in which N-CAM in solution was used, the reaction was terminated by the addition of $20 \mu \mathrm{l}$ "SDS-stop solution" (Hemmings et al., 1984). The reaction mixture was heated at $90^{\circ} \mathrm{C}$ for $1 \mathrm{~min}$ and subjected to discontinuous SDS-PAGE (Laemmli and Favre, 1973). In assays where N-CAM bound to antibody coupled to Sepharose CL-2B was used, the reaction was stopped by the addition of $1 \mathrm{ml}$ Buffer $D$ and the beads were washed twice in this buffer and twice in $10 \mathrm{~mm}$ HEPES, pH 7.4. The beads were resuspended in $100 \mu \mathrm{H}_{2} \mathrm{O}, 20 \mu \mathrm{l}$ SDSstop solution was added, and the samples werc processcd for SDS-PAGE as described above. The SDS-polyacrylamide gels were fixed, stained, destained, dried, and subjected to autoradiography as described by Ueda and Greengard (1977). In some experiments, the phosphorylated bands were excised from the gel and ${ }^{32} \mathbf{P}$ incorporation was quantitated by liquid-scintillation spectrometry.

Tissue culture. Embryonic chicken brain was cultured as previously described (Cunningham et al., 1983). Embryonic mouse tectal reaggre- gate cultures prepared by a modification of the method of Garber and Moscona (1972) were the gift of Dr. I. Shalaby and Dr. N. Rosen. Reaggregate cultures were labeled after 1, 2, or 3 weeks of growth.

I'issue labeling. For labeling with ${ }^{32} \mathrm{P}$-orthophosphoric acid, dispersed brain tissue or tectal reaggregates were resuspended in phosphate-free MEM supplemented with $15 \mathrm{mM}$ HEPES, pH $7.4(1 \mathrm{ml} /$ brain or $1 \mathrm{ml} /$ gm reaggregate protein, respectively) containing $1 \mathrm{mCi} / \mathrm{ml}{ }^{32} \mathrm{P}$-orthophosphoric acid. The tissue was incubated for $12-18 \mathrm{hr}$ at $37^{\circ} \mathrm{C}$ and then was collected by sedimentation and washed once with phosphatefree medium. The washed tissue was homogenized with a glass-Teflon homogenizer at $2100 \mathrm{rpm}$ (dispersed brain tissue) or sonicated in Buffer $\mathrm{D}$ (reaggregate cultures). The tissue extract was clarified by centrifugation at $100,000 \times g$ for $30 \mathrm{~min}$, and the N-CAM was immunoprecipitated from the supernatant using either anti-chicken N-CAM or antirodent N-CAM coupled to Sepharose CL-2B (Chuong et al., 1982; Hoffman et al., 1982).

Phosphatase assays. N-CAM $(1-5 \mu \mathrm{g})$ was phosphorylated by GSK-3 or labeled with ${ }^{3}$ P-orthophosphoric acid in vivo and immunoprecipitated, as described above. Dephosphorylation of N-CAM by protein phosphatase $2 \mathrm{~A}$ (final concentration, $0.5 \mathrm{U} / \mathrm{ml}$ ) was performed in a buffer containing $50 \mathrm{~mm}$ Tris (pH 7.0), $0.1 \mathrm{~mm}$ EDTA, $1 \mathrm{~mm}$ $\mathrm{MnCl}_{2}$, and $15 \mathrm{~mm} \beta$-mercaptoethanol. Dephosphorylation by potato acid phosphatase (final concentration, $0.024 \mathrm{U} / \mathrm{ml}$ ) was performed in a buffer containing $50 \mathrm{~mm}$ piperazine- $N, N^{\prime}$-bis [2-ethanesulfonate] (PIPES; $\mathrm{pH} 6.5), 1 \mathrm{mg} / \mathrm{ml} \mathrm{BSA}$, and $15 \mathrm{~mm} \beta$-mercaptoethanol. Dephosphorylation by alkaline phosphatase (final concentration, $0.26 \mathrm{U} / \mathrm{ml}$ ) was performed in a buffer containing $10 \mathrm{~mm}$ glycine ( $\mathrm{pH} 9.8$ ) and $1 \mathrm{~mm}$ $\mathrm{MgCl}_{2}$. To measure dephosphorylation by endogenous embryonic chicken brain phosphatases, extracts were prepared from $9 \mathrm{~d}$ embryonic chicken brain using PBS containing $0.5 \%$ nonidet $\mathrm{P}-40$ (NP-40) (Hoffman et al., 1982). Dephosphorylation reaction volumes were 100-500 $\mu \mathrm{l}$, and samples were incubated at $30-37^{\circ} \mathrm{C}$ for $10 \mathrm{~min}$ to $2 \mathrm{hr}$, as indicated, after which time the samples were subjected to SDS-PAGE and autoradiography as described above.

Miscellaneous techniques. Two-dimensional peptide mapping was performed as described by Detre et al. (1984) with the following modifications: (1) either $50 \mu \mathrm{g} / \mathrm{ml}$ thermolysin or $50 \mu \mathrm{g} / \mathrm{ml}$ each of both trypsin and chymotrypsin were used, as indicated, (2) ascending chromatography was performed only once using butanol: pyridine: acetic acid: water (15:10:3:12). Phosphoamino acid hydrolysis, chromatography, and detection were performed as described by Nairn and Greengard (1987). An $S_{2}$ fraction was prepared by homogenizing adult mouse brain in a 10-fold excess of PBS (Hollnam et al., 1982), centrifuging at $10,000 \times g$ for $20 \mathrm{~min}$, and collecting the supertanant. N-CAM was desialylated as described by Hoffman et al. (1982) or Cunningham et al. (1983). Protein concentrations were determined by a modification of the method of Lowry as described by Peterson (1977).

\section{Results}

Characterization of $N$-CAM phosphorylation in culture

The studies of N-CAM phosphorylation in culture were carried out using either chicken or mouse brain. The $\mathrm{Id}$, sd, and ssd polypeptides of mouse N-CAM closely resemble those of chicken N-CAM (85\% amino acid identity; Hemperly et al., 1986b; Barthels et al., 1987; Small et al., 1987; Barbas et al., 1988). Chicken N-CAM is phosphorylated on both seryl and threonyl residues (Sorkin et al., 1984), whereas mouse N-CAM has been reported to be phosphorylated only on seryl residues (Gennarini et al., 1984).

In an initial attempt to further characterize the phosphorylation sites in N-CAM, embryonic chicken brain tissue was incubated with ${ }^{32} \mathrm{P}$-orthophosphoric acid and the N-CAM isolated from extracts by immunoprecipitation and analyzed by SDS PAGE. Since embryonic N-CAM contains polysialic acid (Cunningham et al., 1983; Finne et al., 1983), the migrations of the ${ }^{32} \mathrm{P}$-labeled ld and sd polypeptides were heterodisperse and overlapped. Two-dimensional thermolytic peptide mapping of the mixture of the ld and sd polypeptides revealed a complex pattcrn of 6 major phosphorylated peptides (Fig. 1C). Six similar ther- 
A

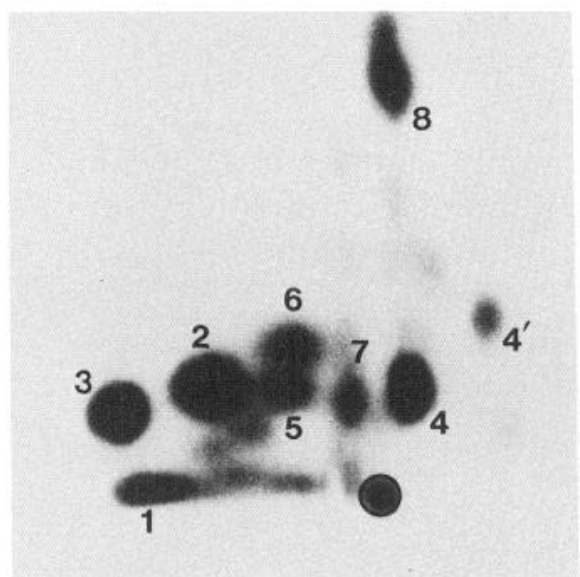

B

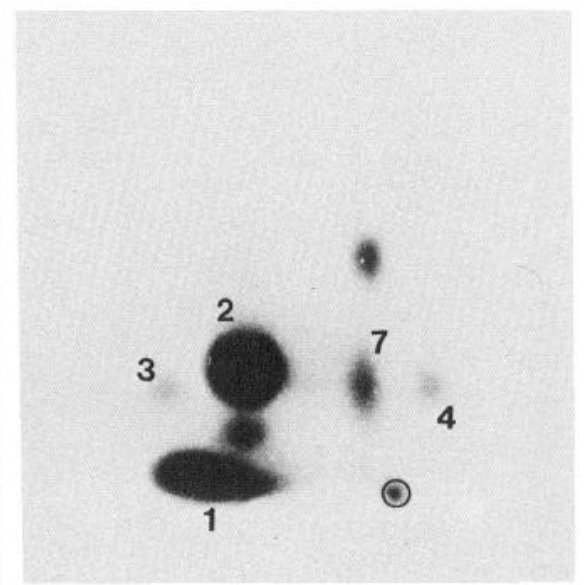

C

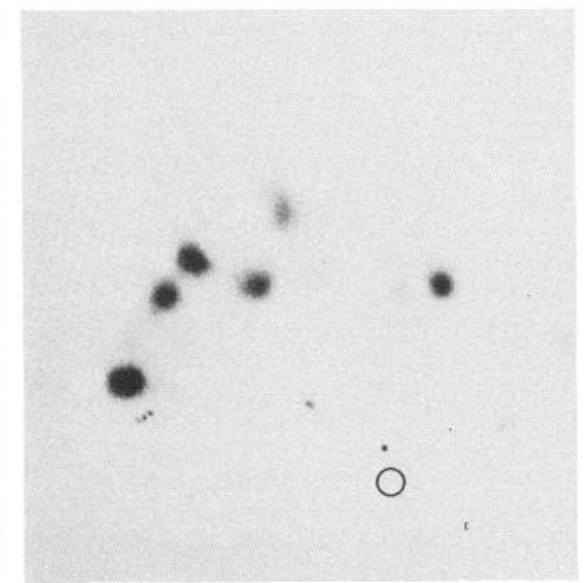

Figure 1. Comparison of phosphorylation sites in the 2 major polypeptides of mouse N-CAM and in sialylated chicken N-CAM. N-CAM was labeled in culture with ${ }^{32} \mathrm{P}$-orthophosphoric acid and isolated on anti-N-CAM-sepharose. Mouse N-CAM, digested with neuraminidase ( $A$ and $B$ ) or untreated chicken N-CAM (C), was detected by SDS-PAGE, excised from the gel, and subjected to 2-dimensional thermolytic peptide mapping and autoradiography as described in Materials and Methods. Electrophoresis (O, origin) was in the horizontal dimension (negative pole, left) and chromatography was in the vertical dimension. A, Autoradiogram of the thermolytic peptide map of the ld polypeptide of mouse N-CAM phosphorylated in culture. $B$, Autoradiogram of the thermolytic peptide map of the sd polypeptide of mouse N-CAM phosphorylated in culture. Peptides numbered $1-4$ and 7 were common to both N-CAM polypeptides. $C$, Autoradiogram of the thermolytic peptide map of fully sialylated chicken N-CAM phosphorylated in culture.

molytic peptides were found in ${ }^{32} \mathrm{P}$-labeled N-CAM obtained from embryonic chicken brain labeled in ovo (data not shown).

To compare the phosphorylation sites in the ld and sd $\mathrm{N}-\mathrm{CAM}$ polypeptides, N-CAM was isolated from cultures of embryonic mouse tectal reaggregates. In these cultures, N-CAM could be labeled with ${ }^{32} \mathrm{P}$-orthophosphoric acid to a higher specific activity than in embryonic chicken brain tissue. N-CAM was isolated by immunoprecipitation and digested with neur- aminidase to remove the polysialic acid, and the ld and sd polypeptides were separated by SDS-PAGE. The ld and sd polypeptides were individually digested with thermolysin and 2-dimensional peptide mapping performed. Two major phosphopeptides were produced from the sd polypeptide (Fig. $1 B$, peptides 1 and 2), both of which comigrated with phosphopeptides found in the ld species (Fig. 1A). There were several minor phosphopeptides present in the sd polypeptide (Fig. 1B, peptides

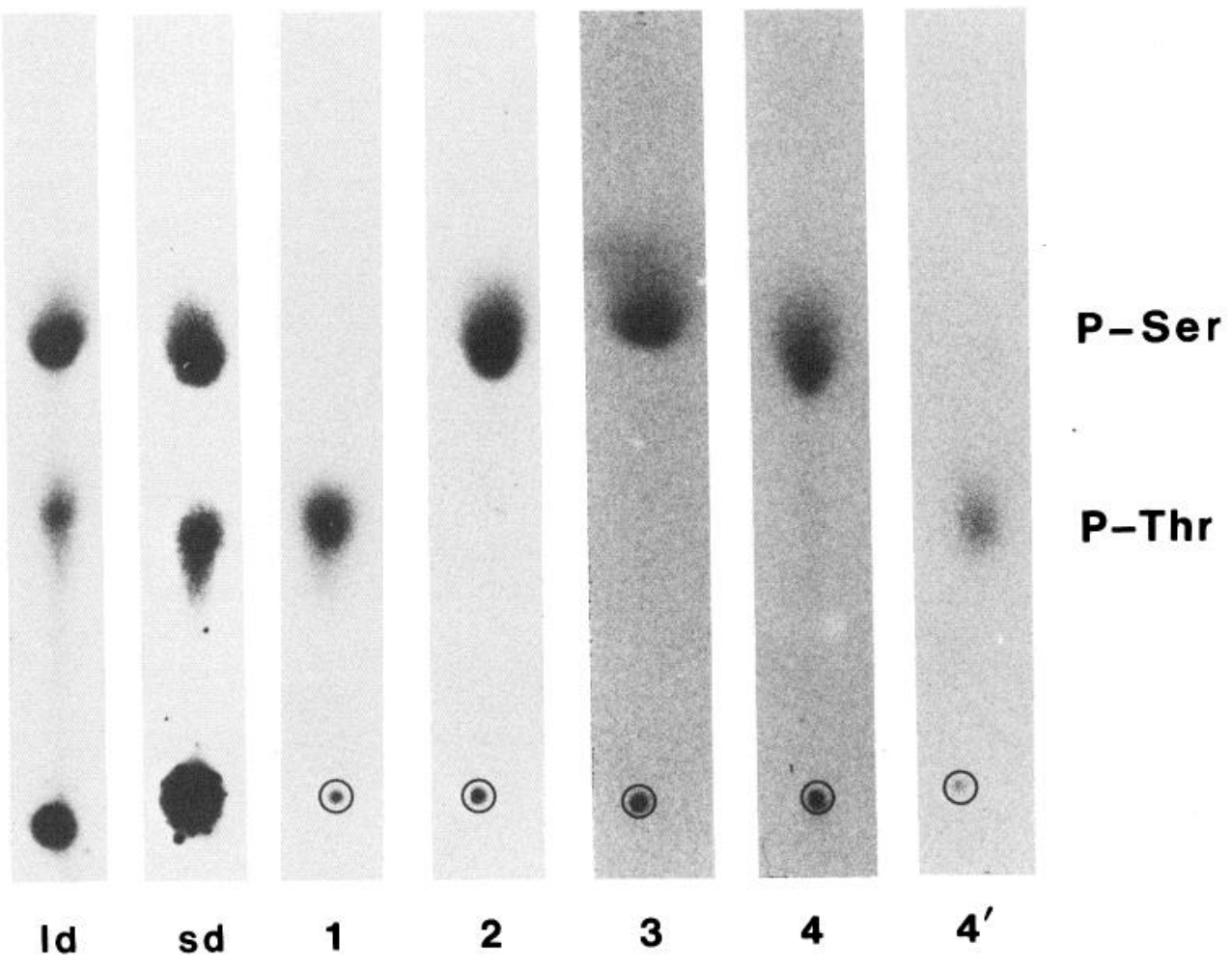

Figure 2. Phosphoamino acid analysis of the 2 major polypeptides of mouse N-CAM phosphorylated in culture. The ld and sd polypeptides of mouse N-CAM phosphorylated in culture were isolated and digested with thermolysin as indicated in the legend to Figure 1. Aliquots of the total digests of the ld and sd polypeptides, or of peptides $I-$ 4 and $4^{\prime}$ obtained following separation of the ld digest, were hydrolyzed with $6 \mathrm{~N} \mathrm{HCl}$ under vacuum for $2 \mathrm{hr}$ and 1-dimensional phosphoamino acid analysis was performed. The position of unlabeled phosphoserine $(P$-Ser $)$ and phosphothreonine $(P-T h r)$ standards was determined by staining of the cellulose plate with ninhydrin. Peptides $1-$ 4 and 7 from the sd species had identical phosphoamino acid compositions to the same peptides derived from the ld species (data not shown). 
Figure 3. Phosphorylation of N-CAM by the soluble fraction of rat brain. Purified chicken N-CAM was incubated with $\gamma$ - $^{32} \mathrm{P}$-ATP and rat brain fractions as indicated, and samples were subjected to SDS-PAGE and autoradiography. Lane 1, N-CAM alone; lane 2, $\mathrm{N}-\mathrm{CAM}$ plus soluble fraction $(5 \mu \mathrm{g}$ total protein); lane $3, \mathrm{~N}-\mathrm{CAM}$ plus DEAE flow-through fraction of rat forebrain supernatant ( $1 \mu \mathrm{g}$ total protein). Aliquots assayed in lanes 2 and 3 corresponded to equal volume of the initial extract. Reaction mixtures were incubated under standard conditions for 5 min with $5 \mu \mathrm{g} \mathrm{N}$-CAM. The broad phosphorylated band of $M_{r} \approx 200,000$ is sialylated N-CAM (Hoffman et al., 1982). Material at the top of the gel is probably aggregated N-CAM. Molecular weights (in $\mathrm{kDa}$ ) of standard proteins are indicated in this and all subsequent autoradiograms of SDSpolyacrylamide gels.

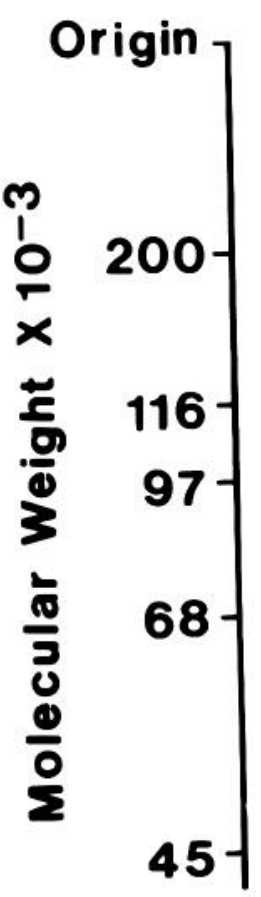

3,4 , and 7) that were found in the ld polypeptide as major phosphopeptides (Fig. 1 $\mathrm{A}$ ). In addition, there were several phosphopeptides present in the ld polypeptide that were not found in the sd polypeptide (Fig. $1 A$, peptides $4^{\prime}, 5,6$, and 8 ). The detection of additional phosphopeptides in the larger N-CAM species suggests that there are phosphorylation sites in the difference region, consistent with earlier results from studies of chicken N-CAM (Sorkin et al., 1984). The presence of relatively low amounts of phosphopeptides 3 and 4 in the sd polypeptide raised the possibility that some of the radioactivity in the sd region of the gel resulted from proteolytic breakdown of the ld polypeptide. Although we cannot totally exclude this possibility, we believe it is unlikely since the addition of a cocktail of protease inhibitors to the extraction and immunoprecipitation steps had no effect on the pattern obtained.

In contrast to earlier results (Gennarini et al., 1984), phosphoamino acid analysis of mouse 1d and sd polypeptides showed that both contained phosphoserine and phosphothreonine (Fig. 2). The sd polypeptide had a higher ratio of phosphothreonine to phosphoserine consistent with the phosphoamino acid content of the individual thermolytic peptides. Only phosphothreonine was detected in peptide 1 (Fig. 2), and only phosphoserine was detected in peptides 2-8 (Fig. 2 and data not shown). In the ld chain peptide 4 ' contained phosphothreonine (Fig. 2) with a trace of phosphoserine, which is not apparent from the exposure of the autoradiogram shown.

\section{Partial purification of a protein kinase activity that phosphorylates $N$-CAM}

In an initial attempt to characterize the protein kinase(s) responsible for the phosphorylation of N-CAM, we incubated purified chicken N-CAM with either purified protein kinases or extracts from brain. Neither native nor desialylated N-CAM were substrates for the second-messenger-regulated protein ki- nases cyclic AMP-dependent protein kinase, cyclic GMP-dependent protein kinase, calcium/calmodulin-dependent protein kinase I, II or III, or protein kinase C under our assay conditions (data not shown). A protein kinase activity that could phosphorylate purified N-CAM was identified in cytosolic brain extracts from several different species. Phosphorylation of N-CAM by brain extracts was detected by incubating purified N-CAM with $\gamma-{ }^{32} \mathrm{P}$-ATP, $\mathrm{Mg}^{2+}$, and the soluble fraction of rat (Fig. 3, lane 2), chicken or bovine brain (data not shown). N-CAM was not phosphorylated when incubated with the particulate fraction from brain of any species tested (data not shown). The kinase activity that phosphorylated N-CAM was purified from embryonic chicken, adult rat, and bovine brains, as well as from rabbit skeletal muscle, with similar results. The purification from rat brain is outlined here.

Fifty rat forebrains were homogenized and centrifuged at $150,000 \times g$ for 45 min (McGuinness et al., 1985), and the soluble fraction was applied to a DEAE-cellulose column $(5 \times$ $10 \mathrm{~cm}$ ) equilibrated with Buffer $\mathrm{A}$. The flow-through contained significantly more than $100 \%$ of the applied N-CAM kinase activity (Fig. 3, lane 3), suggesting the presence of an inhibitor of this activity in the soluble fraction which was retained by the DEAE-cellulose column. Material in the flow-through was applied to a phosphocellulose column $(5 \times 5 \mathrm{~cm})$ equilibrated with Buffer A. The column was washed with 2 volumes of Buffer A and eluted with a linear gradient of $0-0.3 \mathrm{M} \mathrm{NaCl}$; N-CAM kinase activity eluted with a peak at $0.08 \mathrm{M} \mathrm{NaCl}$ (Fig. 4). The peak fractions were pooled, and solid ammonium sulfate was added to $65 \%$ saturation. After centrifugation at $10,000 \times g$ for $30 \mathrm{~min}$, the pellet (containing $>95 \%$ of kinase activity) was resuspended in Buffer B and applied to an Ultrogel AcA44 gel filtration column $(2.5 \times 80 \mathrm{~cm})$. N-CAM kinase activity eluted with an apparent $M_{r}$ of $\approx 50,000$ (Fig. 5). The active fractions were pooled and applied to a column of Affigel blue $(2 \times 10$ 


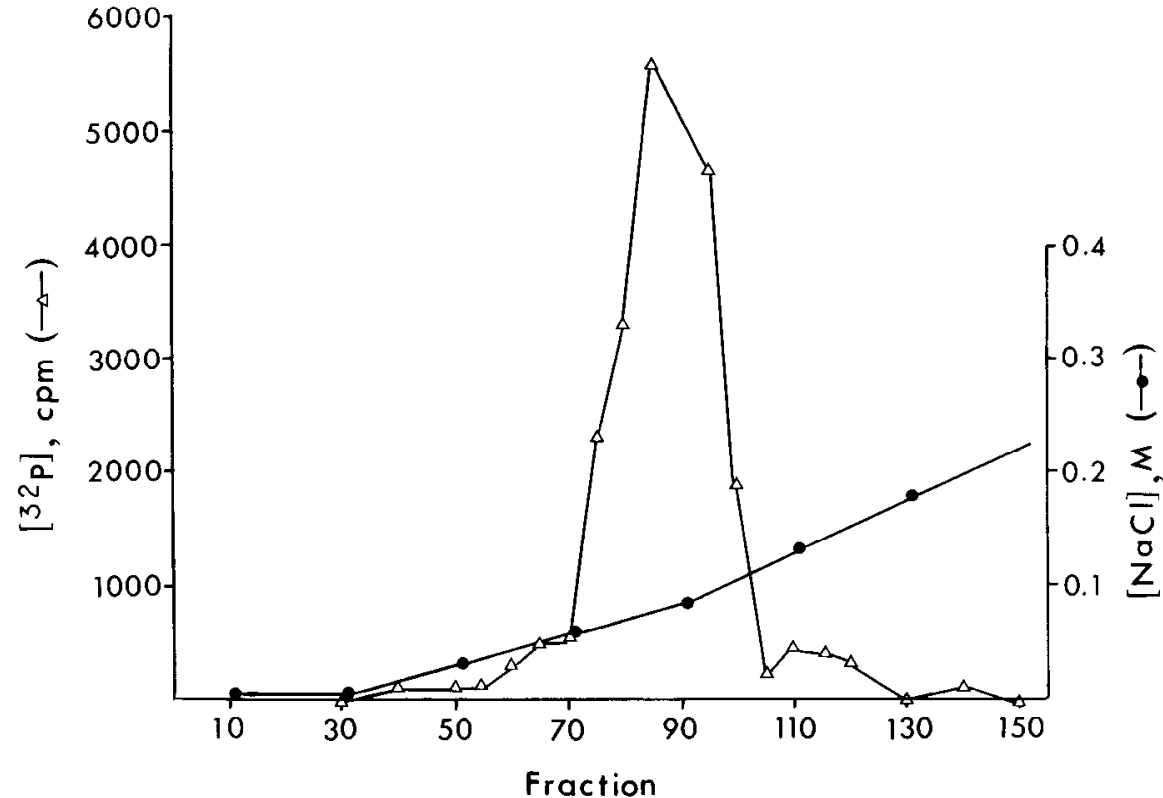

Figure 4. Chromatography of N-CAM kinase activity on phosphocellulose. The flow-through from a DEAE-cellulose column was applied directly to a phosphocellulose column $(5 \times 5 \mathrm{~cm})$ equilibrated with Buffer $\mathrm{A}$. The column was washed with Buffer $\mathrm{A}$ and eluted with a linear gradient of $0-0.3 \mathrm{M} \mathrm{NaCl}$ in Buffer A. The flow rate was $100 \mathrm{ml} / \mathrm{hr}$, and $5 \mathrm{ml}$ fractions were collected. Aliquots $(5 \mu l)$ of every fifth fraction were assayed for $\mathrm{N}$-CAM kinase activity $(\mathrm{cpm}$ ${ }^{32} \mathrm{P}$ incorporated into purified N-CAM was determined by SDS-PAGE and liquid-scintillation spectrometry) using the standard assay conditions. cm) equilibrated with Buffer $B$. The column was eluted with a linear gradient of $0.05-2.0 \mathrm{M} \mathrm{NaCl} ; \mathrm{N}-\mathrm{CAM}$ kinase activity cluted with a broad peak at 1.0-1.2 $\mathrm{M} \mathrm{NaCl}$ (Fig. 6). Active fractions that contained only one kinase activity based on substrate specificity studies (see below) were pooled, concentrated against dry sucrose, dialyzed against Buffer $\mathrm{C}$, and stored at $-20^{\circ} \mathrm{C}$ until use.

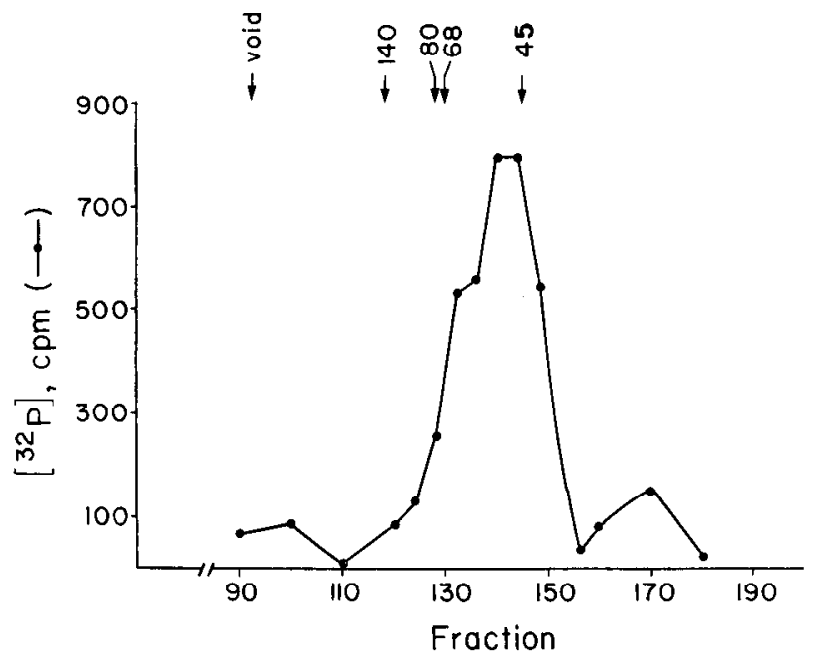

Figure 5. Gel filtration of N-CAM kinase activity. The peak fractions from the phosphocellulose column were pooled, precipitated with ammonium sulfate at $65 \%$ saturation, and the resuspended pellet applied to an Ultrogel AcA44 column $(2.5 \times 80 \mathrm{~cm})$ equilibrated with Buffer B. The flow rate was $20 \mathrm{ml} / \mathrm{hr}$ and $2.5 \mathrm{ml}$ fractions were collected. Aliquots $(10 \mu \mathrm{l})$ were assayed for N-CAM kinase activity using the standard assay. Arrows indicate the positions of elution of blue dextran (void volume), and the molecular-weight standards, lactate dehydrogenase $(140,000)$, transferrin $(80,000)$, BSA $(68,000)$, and ovalbumin $(45,000)$.

\section{Comparison of N-CAM kinase with glycogen synthase} kinase-3

The N-CAM kinase activity purified as described above was not regulated by any of the known second messengers, for example, cAMP or $\mathrm{Ca}^{2+}$. Comparison of the properties of the kinase activity with those of known "independent" kinases re-

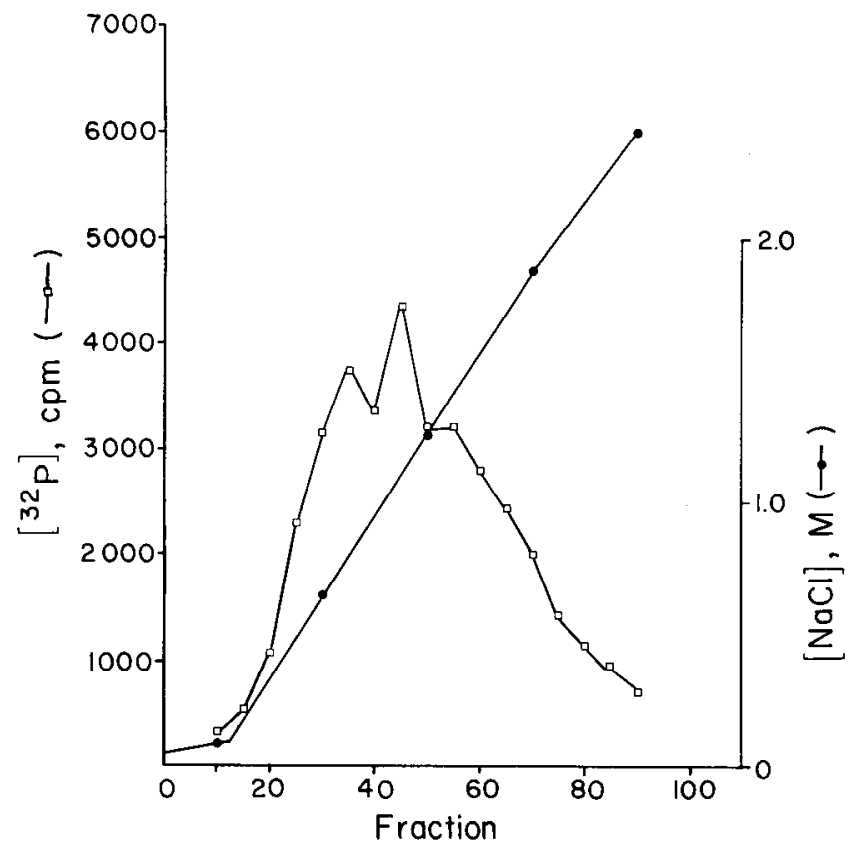

Figure 6. Chromatography of N-CAM kinase activity on Affigel blue. The peak fractions from the gel-filtration column were pooled and applied to an Affigel blue column $(2 \times 10 \mathrm{~cm})$ equilibrated with Buffer B, washed with $0.3 \mathrm{M} \mathrm{NaCl}$ in Buffer $\mathrm{B}$, and eluted with a linear gradient of $0.05-2 \mathrm{M} \mathrm{NaCl}$ in Buffer B. The flow rate was $20 \mathrm{ml} / \mathrm{hr}$, and $1 \mathrm{ml}$ fractions were collected. Aliquots $(5 \mu \mathrm{l})$ were assayed for N-CAM kinase activity using the standard assay. 
A.

B.

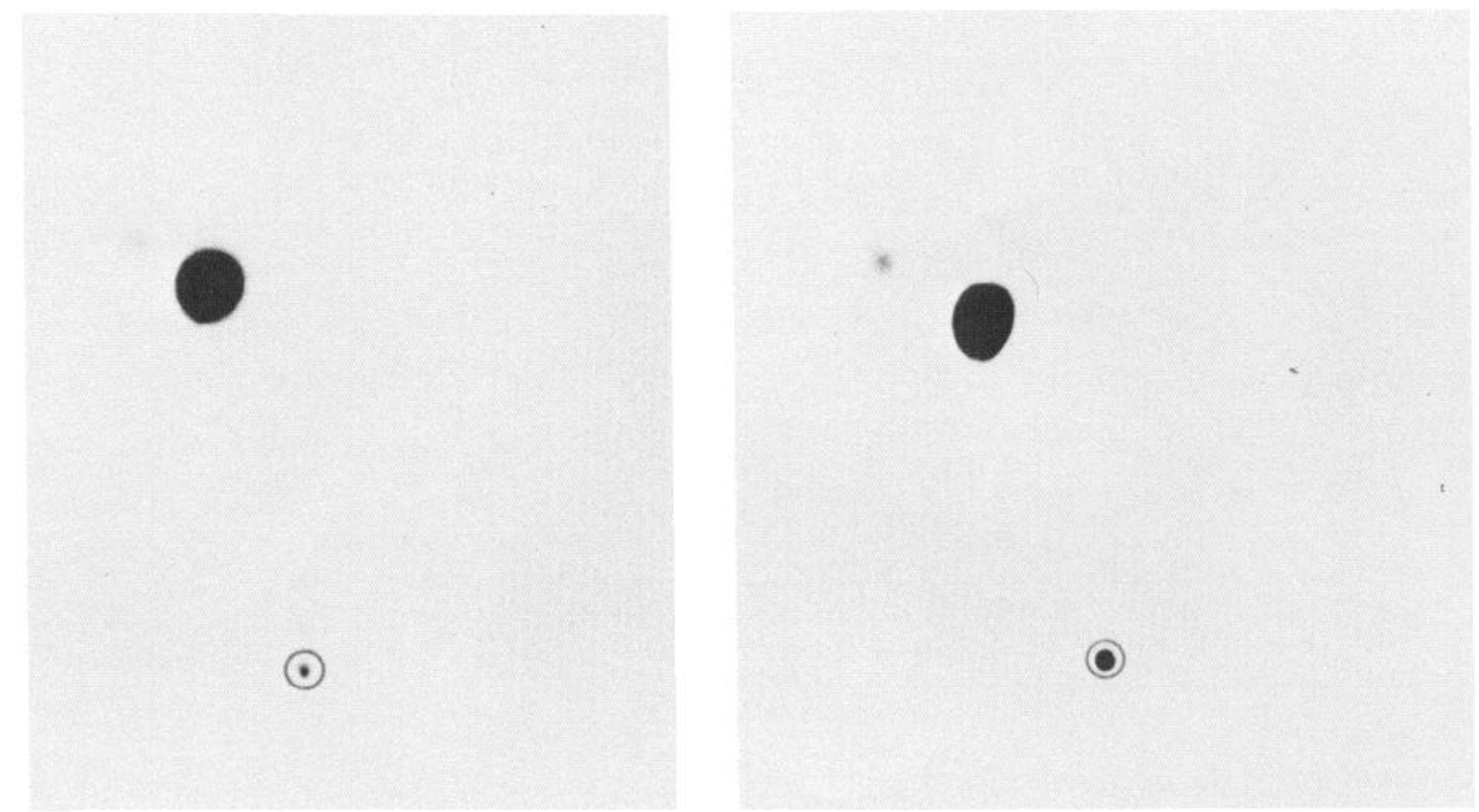

Figure 7. Phosphopeptide mapping of glycogen synthase phosphorylated by N-CAM kinase and by GSK-3. Rabbit muscle glycogen synthase was phosphorylated by $(A)$ the partially purified N-CAM kinase described above or $(B)$ GSK-3 purified from rabbit skeletal muscle. Two-dimensional phosphopeptide mapping was performed as described in Figure 1 except that trypsin plus chymotrypsin replaced thermolysin.

vealed a striking similarity with GSK-3 in chromatographic behavior on DEAE-cellulose, phosphocellulose, gel filtration, and hydroxylapatite. GSK-3 is one of several protein kinases that phosphorylate glycogen synthase and has been purified from rabbit skeletal muscle using glycogen synthase as a substrate (Rylatt et al., 1980; Hemmings et al., 1982a; Woodgett and Cohen, 1984). Comparison of the 2-dimensional tryptic/chymotryptic phosphopeptide maps of glycogen synthase phosphorylated by the kinase that phosphorylates N-CAM, purified as described above (Fig. 7A) and by authentic rabbit skeletal muscle GSK-3 (Woodgett and Cohen, 1984) (Fig. 7B) indicated that the 2 kinases phosphorylated the same peptide.

In addition to glycogen synthase, there are only 2 other wellcharacterized substrates for GSK-3, the type II regulatory subunit of cyclic AMP-dependent protein kinase $\left(\mathrm{R}_{\mathrm{II}}\right)$ and phosphatase inhibitor-2 (I-2) (Hemmings et al., 1982b, c). The kinase from brain phosphorylated both of these substrates at rates comparable to N-CAM and glycogen synthase (see below). In ad-

Table 1. Relative rates of phosphorylation of N-CAM and glycogen synthase by GSK-3 partially purified from rat brain, and of N-CAM and casein by CK I partially purified from rat brain

\begin{tabular}{llll} 
& N-CAM & Glycogen synthase & Casein \\
\hline GSK-3 & $2.96 \pm 0.28^{a}$ & $4.56 \pm 0.60^{a}$ & N.D. \\
CK I & $169 \pm 4^{b}$ & N.D. & $94 \pm 1^{b}$
\end{tabular}

Substrate concentrations were $1.25 \mu \mathrm{M}$ for GSK-3 assays and $1.0 \mu \mathrm{M}$ for CK assays.

N.D., not determined.

" $\mathrm{nmol} / \mathrm{mg} / \mathrm{min}$.

${ }^{h} \mathrm{pmol} / \mathrm{ml} / \mathrm{min}$. dition, the kinase that phosphorylated N-CAM coeluted on CM-cellulose with the kinase that phosphorylated $\mathrm{R}_{\mathrm{II}}$ and I-2, suggesting that all 3 proteins were substrates for the same protein kinase. Thus, the protein kinase partially purified from brain using N-CAM as a substrate is very similar to rabbit skeletal muscle GSK-3 on the basis of its chromatographic properties, sites of glycogen synthase phosphorylation, and substrate specificity. Furthermore, authentic rabbit skeletal muscle GSK-3 phosphorylated purified N-CAM at rates comparable to the enzyme purified from chicken brain (data not shown). We therefore refer to this protein kinase as GSK-3.

\section{Phosphorylation of the N-CAM polypeptides by GSK-3 and casein kinase $I$ and $I I$}

The phosphorylation of the ld and sd polypeptides of N-CAM by GSK-3 and by 2 other "independent" protein kinases, namely, casein kinases I and II, was investigated in more detail. Embryonic chicken N-CAM was phosphorylated by GSK-3, the samples incubated either without or with neuraminidase, and resolved by SDS-PAGE. GSK-3 phosphorylated both the ld and sd polypeptides, with the ld polypeptide being phosphorylated to a greater extent (Fig. $8 A$ ). Both the ld and sd polypeptides were also phosphorylated by casein kinase I (CK I; Fig. $8 B$ ) but not by CK II. In these experiments the mass ratio of $M_{r}=$ 170,000 to $M_{r}=140,000$ was about $0.9: 1.0$, and the proportion of ${ }^{32} \mathrm{P}$ incorporated into the 2 polypeptides was about $5: 1$; thus, the larger polypeptide was phosphorylated by both enzymes to a greater extent than was the smaller. The third polypeptide of N-CAM, the ssd polypeptide, which contains no cytoplasmic domain, was not a substrate for GSK-3, CK I, or CK II. Mouse and rat N-CAM contain ld, sd, and ssd polypeptides similar to those of chicken N-CAM. The phosphorylation of rat N-CAM 


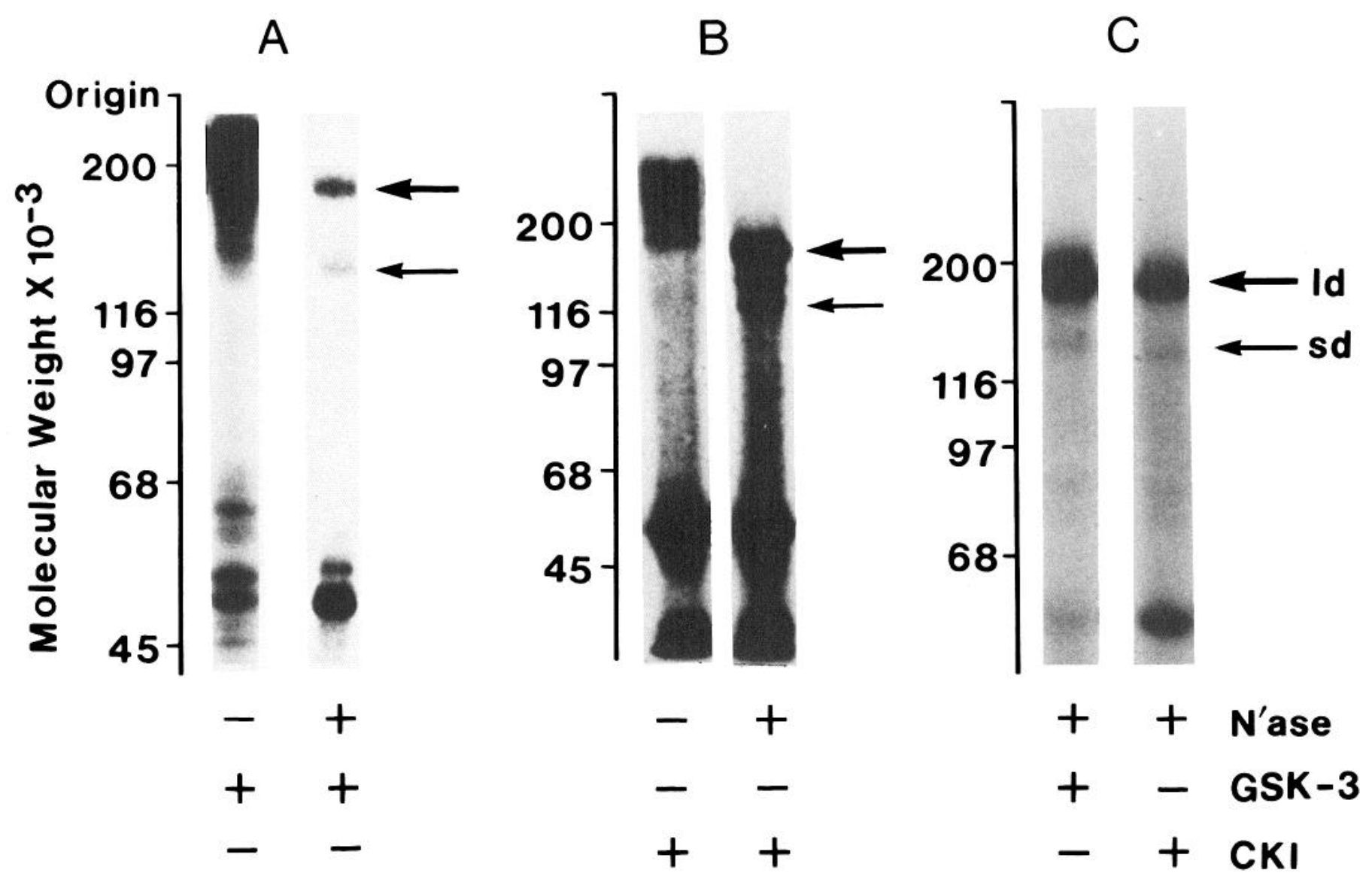

Figure 8. Phosphorylation of chicken and rodent N-CAM by partially purified GSK-3 and CK I. Native (N'ase -) or neuraminidase-digested $\left(\mathrm{N}^{\prime}\right.$ ase + ) N-CAM bound to anti-N-CAM coupled to Sepharose CL-2B was phosphorylated by either GSK-3 or CK I using the standard assay conditions and samples were separated by SDS-PAGE and autoradiography performed. $A$, Embryonic chicken N-CAM phosphorylated by GSK3. $B$, Embryonic chicken N-CAM phosphorylated by CK I. C, Adult rat N-CAM phosphorylated by GSK-3 and CK I. Heavy arrow, ld polypeptide; light arrow, sd polypeptide. The band migrating at $M_{r} \approx 55,000$ is monomeric immunoglobulin heavy chain.

was similar to that of chicken N-CAM, with GSK-3 and CK I phosphorylating the ld and, to a lesser extent, the sd polypeptides (Fig. 8C). Rat N-CAM was not phosphorylated by cyclic AMPdependent protein kinase, cyclic GMP-dependent protein kinase, calcium/calmodulin-dependent protein kinase I, II or III, protein kinase C, or CK II (data not shown).

\section{Kinetics of phosphorylation of N-CAM by GSK-3 and CK I}

If N-CAM is a physiological substrate for GSK-3 or CK I, it should be phosphorylated rapidly, with a low $K_{m}$ and to a high stoichiometry. The rate of phosphorylation of N-CAM by GSK-3 was $65 \%$ that of glycogen synthase (Table 1). The rate of phosphorylation of N-CAM by CK I was $180 \%$ that of casein. Analysis of the phosphorylation of N-CAM by partially purified GSK-3 using a Lineweaver-Burk plot gave an approximate $K_{m}$ of $24 \mu \mathrm{M}$ and a $V_{\max }$ of $120 \mathrm{nmol} / \mathrm{mg} / \mathrm{min}$ (not shown). Purified $\mathrm{N}$-CAM $(0.5 \mu \mathrm{mol})$ was incubated with GSK-3 using the standard assay for various periods of time. The phosphorylation of $\mathrm{N}$-CAM was essentially complete after $30 \mathrm{~min}$ (not shown). Assuming an average molecular weight of 135,000 for N-CAM, the maximum stoichiometry of phosphorylation by GSK-3 was calculated to be $0.9 \mathrm{~mol} / \mathrm{mol}$.

\section{Characterization of $\mathrm{N}-\mathrm{CAM}$ phosphorylation sites}

Two-dimensional thermolytic peptide mapping of chicken N-CAM showed that GSK-3 (Fig. 9A) and CK I (Fig. 9B) both phosphorylated N-CAM on the same peptide. Threonine was the major ( $>95 \%$ ) amino acid phosphorylated by either kinase (Fig. 9C). Similar results were obtained from phosphopeptide mapping and phosphoamino acid analysis of rat N-CAM phosphorylated by GSK-3 or CK I (data not shown).

Most protein kinases act intracellularly, and the observation that the ssd polypeptide was not a substrate for GSK-3 or CK I, suggested that the N-CAM phosphorylation site is intracellular. To investigate whether CK I and GSK-3 phosphorylated $\mathrm{N}-\mathrm{CAM}$ on its intracellular domain, right-side-out embryonic chicken brain vesicles (Hoffman and Edelman, 1983) were incubated with CK I and $\gamma$-32P-ATP. No significant phosphorylation of either the ld or sd polypeptides of N-CAM was observed when CK I was added in the absence of NP-40 (Fig. 10). However, when $0.5 \% \mathrm{NP}-40$ was present during the reaction, both $\mathrm{N}$-CAM species were phosphorylated by CK I. In contrast, there was no effect of NP-40 on the phosphorylation of purified N-CAM by GSK-3 or CK I. Some N-CAM phosphorylation 
A

B

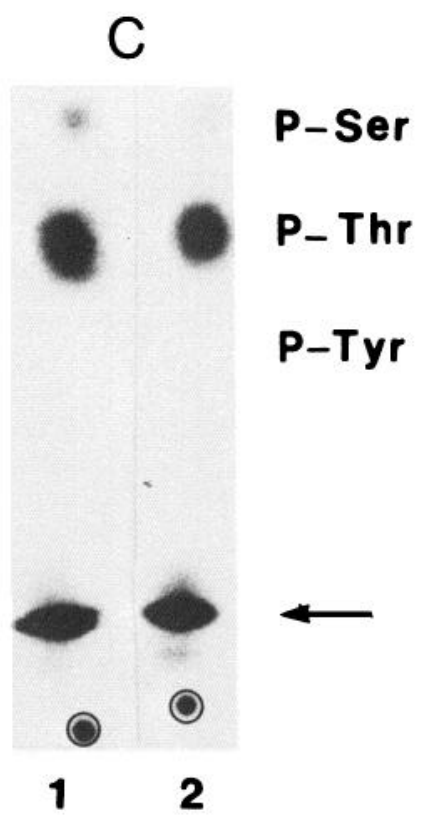

Figure 9. Phosphopeptide mapping and phosphoamino acid analysis of chicken N-CAM phosphorylated in vitro. Two-dimensional phosphopeptide mapping was performed as described in the legend to Figure 1. A, Autoradiogram of the thermolytic peptide map of chicken N-CAM phosphorylated by GSK-3. B, Autoradiogram of the thermolytic peptide map of chicken N-CAM phosphorylated by CK I. $C$, Autoradiogram showing the amino acids phosphorylated in chicken N-CAM by GSK-3 (lane 1$)$ and by CK I (lane 2$)$. The positions of phosphoserine $(P$-Ser), phosphothreonine $(P$ $T h r)$, and phosphotyrosine $(P-T y r)$ were detected by staining with ninhydrin, and radioactivity was quantitated by liquid-scintillation counting. The arrow indicates the position of incompletely hydrolyzed phosphopeptides.

Figure 10. Phosphorylation of $\mathrm{N}-\mathrm{CAM}$ in chicken brain membrane vesicles. Vesicles were incubated in the standard phosphorylation reaction mixture made isotonic with sucrose and containing the following additions: lane 1 , no additions; lane 2, NP-40 alone; lane 3, CK I alone; lane 4, NP-40 and CK I. N-CAM was immunoprecipitated from NP-40-solubilized vesicles and digested with neuraminidase, and the samples were subjected to SDS-PAGE and autoradiography. Heavy arrow, ld polypeptide; light arrow, sd polypeptide.

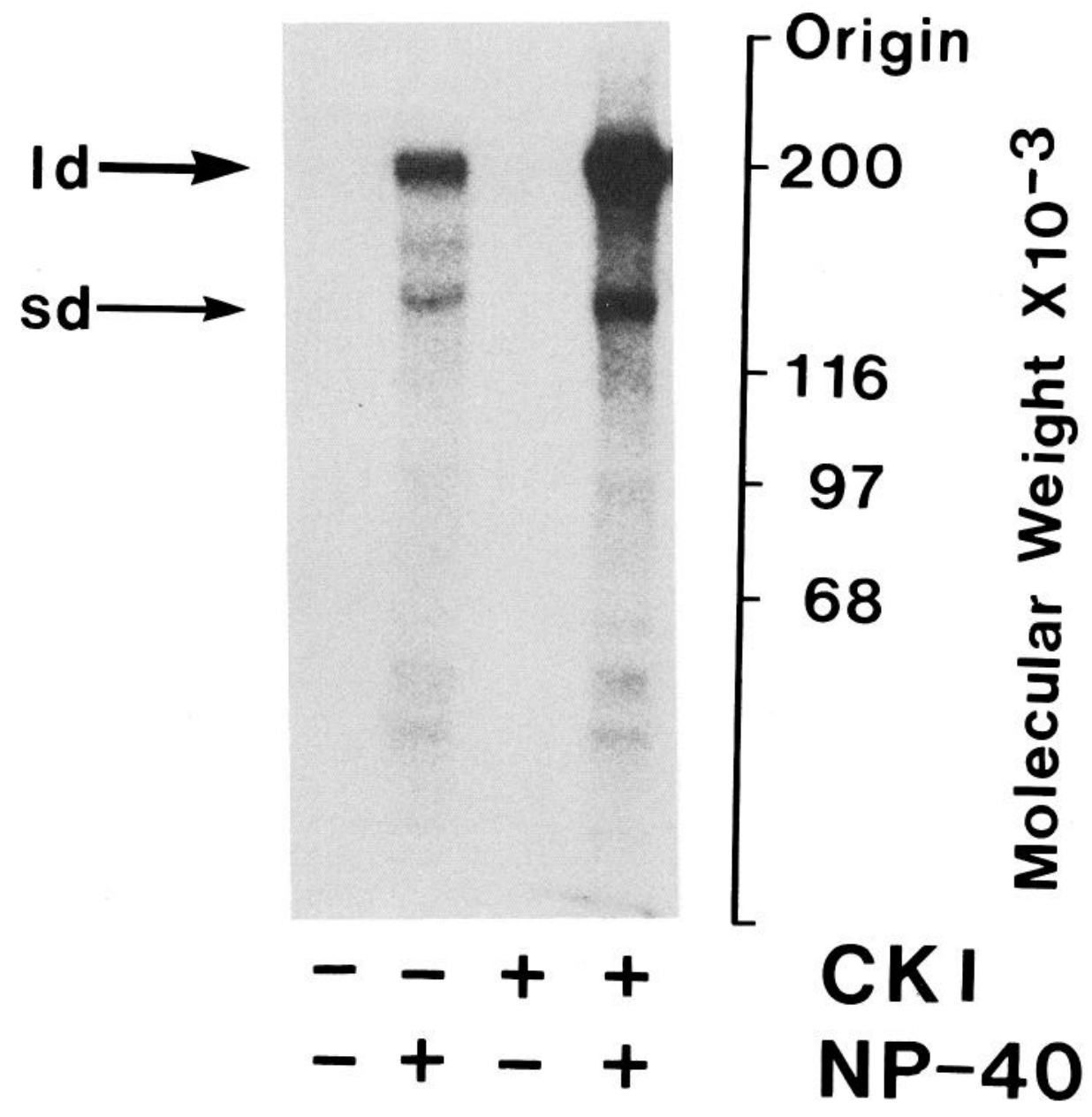


A

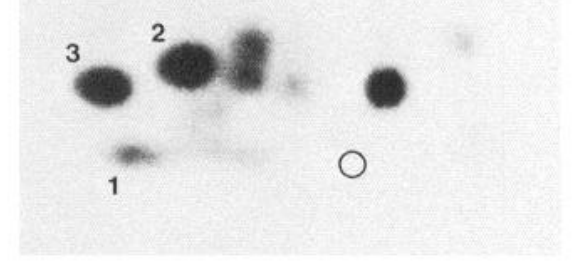

C

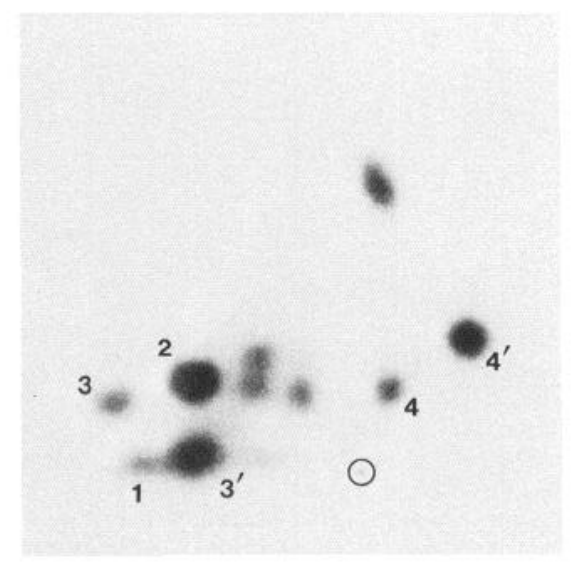

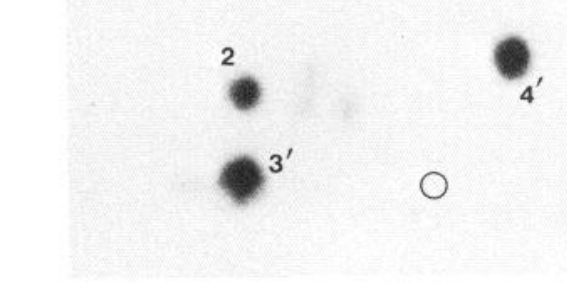

D

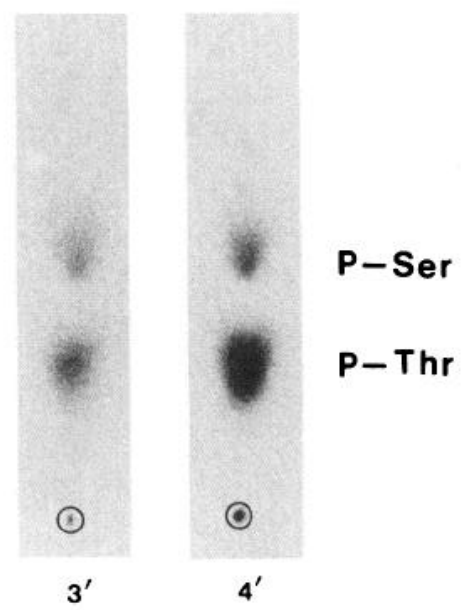

Figure 11. Phosphopeptide mapping of mouse N-CAM phosphorylated first in vivo and then by GSK- 3 in vitro. Twodimensional phosphopeptide mapping was performed as described in Figure 1. A, Autoradiogram of the thermolytic peptide map of embryonic mouse brain ld polypeptide of N-CAM phosphorylated in culture. $B$, Autoradiogram of the thermolytic peptide map of embryonic mouse brain ld polypeptide of N-CAM phosphorylated first in culture followed by phosphorylation with $\gamma^{3{ }^{32} \mathrm{P}-}$ ATP and GSK-3. Peptides $3^{\prime}$ and $4^{\prime}$ indicate the positions of the peptides phosphorylated in vivo which are additionally phosphorylated by GSK- 3 in vitro. Note that because of the higher specific activity of the peptides phosphorylated by GSK-3, the autoradiogram in $B$ was exposed for less time than that in $A$. C, Autoradiogram of a mixture of equal amounts of the thermolytic digests shown in $A$ and $B . D$, Autoradiogram indicating the amino acids phosphorylated in peptides $3^{\prime}$ and 4 ' obtained from the samples separated as shown in $B$. was seen upon the addition of NP-40 alone to the chicken brain vesicles. Phosphorylation by this endogenous N-CAM kinase activity occurred on the same thermolytic peptide phosphorylated by GSK-3 and CK I (data not shown).

GSK-3 phosphorylation sites are usually close to other phosphorylation sites, with which they interact (e.g., Woodgett and Cohen, 1984). To determine whether this was the case for $\mathrm{N}-\mathrm{CAM}$, mouse N-CAM was labeled in culture with ${ }^{32} \mathrm{P}$-orthophosphoric acid and isolated by immunoprecipitation. An aliquot was then further phosphorylated with GSK-3 and $\gamma-{ }^{32} \mathrm{P}-$ ATP, and both samples were digested with neuraminidase and the polypeptides separated by SDS-PAGE. Comparison of the thermolytic phosphopeptide map of the ld polypeptide of N-CAM phosphorylated in culture (Fig. 11A), with that of the ld polypeptide phosphorylated first in culture and then by GSK-3 (Fig. $11 B$ ), revealed that the migration of phosphopeptides 3 and 4 were markedly changed following phosphorylation by GSK-3. Note that because of the higher specific activity of the peptides phosphorylated by GSK-3, the autoradiogram shown in Figure $11 B$ was exposed for a shorter time than that in Figure $11 \mathrm{~A}$. Similar changes in the positions of peptides 3 and 4 were seen in the sd polypeptide (data not shown), where they were present in lower amounts than in the ld polypeptide (see Fig. 1). Analysis of the data shown in Figure 11, as well as results from additional experiments in which peptides $3 / 3^{\prime}$ were present in lower amounts than peptides $4 / 4^{\prime}$, showed that peptide 3 phosphorylated on serine in culture (Fig. 2) was further phosphorylated by GSK-3 on threonine (Fig. 11D) and migrated to the position indicated $\left(3^{\prime}\right)$. Similar analysis as well as mixing experiments (Fig. 11C) showed that peptide 4, phosphorylated on serine in culture, was further phosphorylated by GSK-3 on threonine (Fig. 11D). It then migrated to the same position as peptide $4^{\prime}$, which was labeled in low amounts in culture (see Fig. 1A). The electrophoretic and chromatographic properties of peptide 4' phosphorylated either in culture or following phosphorylation in culture and by GSK-3 were the same as those of the peptide phosphorylated in purified N-CAM by GSK-3 or CK I (Fig. 9).

\section{Phosphatase sensitivity of N-CAM labeled by GSK-3 or in culture}

To further compare the GSK-3/CK I and the in vivo phosphorylation sites, N-CAM phosphorylated under both conditions was incubated with protein phosphatase $2 \mathrm{~A}$, a protein phosphatase with a broad substrate specificity (Ingebritsen and Cohen, 1983). When N-CAM phosphorylated by GSK-3 was incubated with protein phosphatase $2 \mathrm{~A}$ for $45 \mathrm{~min}$, essentially all of the ${ }^{32} \mathrm{P}$ was removed (Fig. 12A). In contrast, after a similar incubation with phosphatase $2 \mathrm{~A}$, chicken N-CAM labeled with ${ }^{32} \mathrm{P}$-orthophosphoric acid in culture remained fully phosphorylated (Fig. 12B).

As the GSK-3/CK I site is readily dephosphorylated in vitro, it is likely that during the isolation of N-CAM this site is dephosphorylated by endogenous phosphatases. Indeed, mammalian brain contains high levels of protein phosphatase $2 \mathrm{~A}$ activity (Ingebritsen et al., 1983). To determine whether chicken brain contains a similar phosphatase activity, N-CAM labeled 


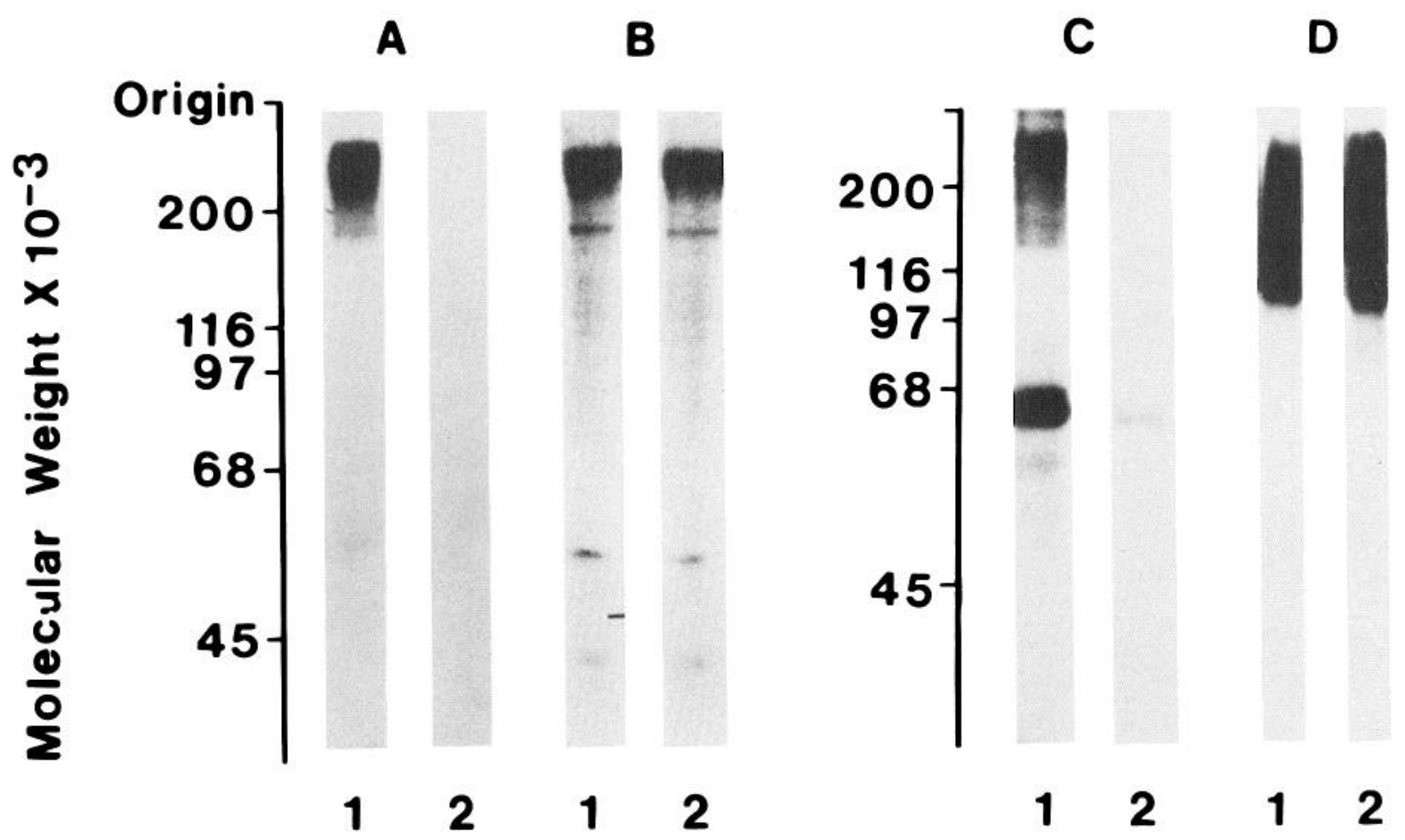

Figure 12. Dephosphorylation of N-CAM. N-CAM was phosphorylated either in vitro or in vivo and dephosphorylated as indicated, and samples were subjected to SDS-PAGE and autoradiography. Purified chicken N-CAM was phosphorylated using GSK-3 and $\gamma-{ }^{32} \mathrm{P}-\mathrm{ATP}(A)$ or phosphorylated with ${ }^{32} \mathrm{P}$-orthophosphoric acid in culture $(B)$, and in both cases incubated without (lane $I$ ) or with (lane 2$)$ protein phosphatase $2 \mathrm{~A}(0.5 \mathrm{U} / \mathrm{ml})$ for 45 min. $C$, N-CAM was phosphorylated using GSK-3 and $\gamma^{-32}$ P-ATP and incubated without (lane 1 ) or with (lane 2 ) an NP-40 extract of embryonic chicken brain for $10 \mathrm{~min}$. $D$. Autoradiogram of an immunoblot of unlabeled N-CAM incubated without (lane 1) or with (lane 2) NP-40 extract of embryonic chicken brain. N-CAM was detected by incubation of the blot with a 1:10,000 dilution of rabbit anti-chicken N-CAM antiserum followed by ${ }^{125} \mathrm{I}$-protein $\mathrm{A}$.

by GSK-3 was incubated with NP-40 extracts of embryonic brain. Eighty-nine percent of the phosphate incorporated into N-CAM by GSK-3 was removed after $10 \mathrm{~min}$ of incubation at $37^{\circ} \mathrm{C}$ (Fig. 12C). This incubation did not result in significant proteolysis of N-CAM (Fig. 12D). Thus, chicken brain, as well as mammalian brain, contains a phosphatase that readily dephosphorylates the GSK-3/CK I site in N-CAM.

All other well-characterized substrates for GSK-3 are phosphorylated only after prior phosphorylation by CK II (Hemmings et al., 1982b; Picton et al., 1982; DePaoli-Roach, 1984). The failure to phosphorylate N-CAM using CK II and the ability of the protein to be phosphorylated by GSK-3 might thus be due to the site(s) for CK II (or another kinase) being fully phosphorylated in isolated N-CAM. The CK II sites in both $R_{I I}$ and glycogen synthase retain significant amounts of phosphate during purification as these sites are poor substrates for endogenous protein phosphatases. They are, however, excellent substrates for potato acid phosphatase (Hemmings et al., 1982b; Picton et al., 1982).

The stability of the phosphate incorporated into N-CAM in vivo was therefore investigated by comparing the abilities of phosphatase $2 \mathrm{~A}$, potato acid phosphatase, and alkaline phosphatase to dephosphorylate mouse N-CAM (Fig. 13A). Potato acid phosphatase removed greater than $80 \%$ of the ${ }^{32} \mathrm{P}$ from $\mathrm{N}$-CAM labeled in culture, while alkaline phosphatase was less effective and, as with chicken N-CAM, phosphatase $2 \mathrm{~A}$ had little or no effect. Incubation with potato acid phosphatase did not result in appreciable proteolysis of N-CAM (Fig. 13B).

To investigate the relationship between the sites phosphorylated by GSK-3 and the sites dephosphorylated by potato acid phosphatase, purified chicken N-CAM was treated with potato acid phosphatase, the phosphatase removed by washing, and the N-CAM then incubated with either GSK-3 or CK II or CK II followed by GSK-3 (Fig. 14). Dephosphorylation with acid phosphatase converted N-CAM to a form that was poorly phosphorylated by either GSK-3 (Fig. 14, lane 2) or CK I (data not shown). N-CAM was not a substrate for CK II despite the acid phosphatase treatment (Fig. 14, lane 3). Furthermore, incubation of dephosphorylated N-CAM with CK II did not convert the protein to a form that was readily phosphorylated by GSK-3 (Fig. 14, lane 4). In addition, after dephosphorylation by acid phosphatase, N-CAM was not phosphorylated by mouse brain extracts (Fig. 14, lanes 5 and 6) or by any of the cyclic nucleotidedependent protein kinases used previously (data not shown). These results suggest that prior phosphorylation on the in vivo sites is a prerequisite for phosphorylation by GSK-3 and CK I.

\section{Discussion}

In the current work we have examined the phosphorylation of $\mathrm{N}-\mathrm{CAM}$ both in vivo and in vitro. The results indicate that differential phosphorylation of the ld and sd polypeptides occurs in vivo and that 2 previously described protein kinases, GSK-3 and CK I, phosphorylate both chains in vitro. Both GSK-3 and CK I are "independent" protein kinases, that is, they have no known physiological activators. GSK-3 phosphorylates 3 other substrates in addition to N-CAM; these are glycogen synthase, inhibitor-2 (Hemmings et al., 1982c), and the regulatory subunit of type II cyclic AMP-dependent protein kinase (Hemmings et al., 1982b). In contrast, CK I phosphorylates a large number of diverse substrates (Hathaway and Traugh, 1982). N-CAM was 

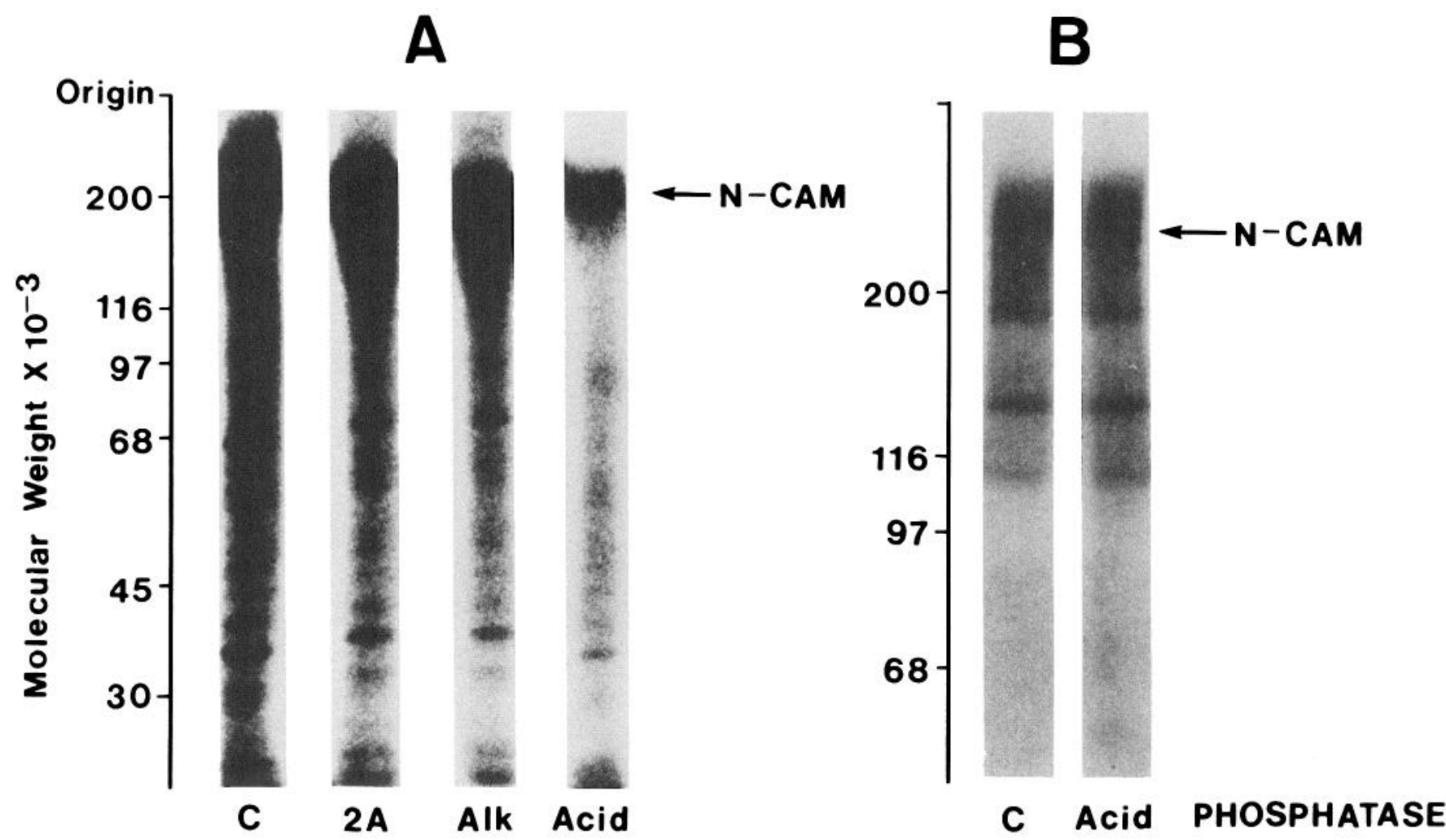

Figure 13. Dephosphorylation of N-CAM by potato acid phosphatase. $A$, N-CAM was phosphorylated in culture and dephosphorylated as indicated, and samples were subjected to SDS-PAGE and autoradiography. Lane $I$, no phosphatase; lane 2, protein phosphatase $2 \mathrm{~A}(0.5 \mathrm{U} / \mathrm{ml}$ for $45 \mathrm{~min})$; lane 3 , alkaline phosphatase $(0.26 \mathrm{U} / \mathrm{ml}$ for $2 \mathrm{hr})$; and lane 4 , potato acid phosphatase $(0.024 \mathrm{U} / \mathrm{ml}$ for $2 \mathrm{hr})$. B, Autoradiogram of an immunoblot of N-CAM incubated without or with acid phosphatase as above, subjected to SDS-PAGE and electrophoretically transferred to nitrocellulose membranes. N-CAM was detected by incubation of the nitrocellulose with a 1:10,000 dilution of rabbit anti-mouse N-CAM antiserum followed by ${ }^{125} \mathrm{I}$-protein $\mathrm{A}$. The arrow indicates the position of N-CAM.

found not to be phosphorylated in vitro by any of the wellcharacterized calcium-dependent or cyclic nucleotide-dependent protein kinases.

Two distinct types of N-CAM phosphorylation sites were distinguished by their susceptibility to phosphorylation and dephosphorylation. The major sites phosphorylated in culture were resistant to dephosphorylation by protein phosphatase $2 \mathrm{~A}$, while the major site labeled by GSK-3 or CK I in vitro (but detected only at low levels in culture) was quite sensitive. These differences suggest the presence of both relatively stable and transient types of phosphorylation of N-CAM, each of which might modulate N-CAM function in different ways.

The 2 types of N-CAM phosphorylation sites apparently interact. N-CAM is poorly phosphorylated by GSK-3 if the sites phosphorylated in culture are first dephosphorylated by potato acid phosphatase. The other known substrates of GSK-3, glycogen synthase, $\mathrm{R}_{\mathrm{II}}$, and I-2, show similar behavior in that each must be phosphorylated by CK II before it can be phosphorylated by GSK-3 (Hemmings et al., 1982b; Picton et al., 1982; DePaoli-Roach, 1984).

Although N-CAM labeled in culture is phosphorylated most prominently on sites not phosphorylated by GSK-3 or CK I, the data suggest that N-CAM is a physiological substrate for GSK-3 and CK I. Peptide 4', the major peptide phosphorylated by GSK-3 is phosphorylated to a small but measurable extent in N-CAM labeled in culture. N-CAM is phosphorylated by GSK-3 and CK I at rates comparable to those for glycogen synthase and casein, respectively (Table 1), as expected for a physiological substrate (Krebs and Beavo, 1979). A kinetic analysis of the phosphorylation of N-CAM by GSK-3 gave $K_{m}$ and $V_{\max }$ values similar to those obtained for physiological substrates of other protein kinases. In addition, GSK-3 phosphorylates $\mathrm{N}-\mathrm{CAM}$ with a stoichiometry of approximately $1 \mathrm{~mol} / \mathrm{mol}$, consistent with N-CAM being a specific substrate for GSK-3, which has previously been found to phosphorylate only 3 other proteins stoichiometrically. Furthermore, GSK-3 and CK I phosphorylate threonyl residues in similar thermolytic peptides in chicken, mouse, and rat N-CAM, suggesting that functional constraints favor the conservation of this site.

There are a number of possible reasons for the low level of phosphorylation of N-CAM on the GSK-3/CK I site in cells labeled in culture. This site may be phosphorylated in the cultured tissue but dephosphorylated by endogenous protein phosphatases during isolation (see Fig. 12), despite the presence of phosphatase inhibitors. Alternatively, in vivo this site may only be phosphorylated in response to a specific stimulus.

There are several explanations of why the phosphorylation of the major in vivo sites were not detected using in vitro assays. The sites phosphorylated in vivo are most likely stoichiometrically phosphorylated, a possibility favored by the observations that much of the phosphate incorporated in culture is resistant to removal by endogenous protein phosphatases (Figs. 12, 13) and that purified N-CAM contains about $3 \mathrm{~mol}$ phosphate $/ \mathrm{mol}$ protein (Hoffman et al., 1982). Moreover, peptide 4 in N-CAM 
Figure 14. Dephosphorylation of the sites phosphorylated on N-CAM in vivo inhibits phosphorylation by GSK-3 and by mouse brain extracts. Embryonic chicken N-CAM was phosphorylated and dephosphorylated as indicated, and samples were subjected to SDS-PAGE and autoradiography. N-CAM was incubated with GSK-3 and $\gamma-{ }^{32} \mathrm{P}-\mathrm{ATP}$ (lane 1 ) or dephosphorylated by potato acid phosphatase and then incubated with $\gamma{ }^{-32} \mathrm{P}-\mathrm{ATP}$ and GSK-3 (lane 2) or CK II (lane 3). N-CAM dephosphorylated by acid phosphatase was incubated with CK II and $\gamma-{ }^{32} \mathrm{P}$-ATP then with GSK-3 and $\gamma-{ }^{32}$ P-ATP (lane 4). N-CAM was incubated with the $S_{2}$ fraction of mouse brain and $\gamma-{ }^{32} \mathrm{P}$-ATP (lane 5) or was dephosphorylated by acid phosphatase and then incubated with the $\mathrm{S}_{2}$ fraction and $\gamma+{ }^{32} \mathrm{P}-\mathrm{ATP}$ (lane 6). PAP, incubation with potato acid phosphatase; $C K I I$, incubation with casein kinase II; $G S K-3$, incubation with glycogen synthase kinase- $3 ; S_{2}$, incubation with an aliquot of mouse brain $\mathrm{S}_{2}$ fraction containing $5 \mu \mathrm{g}$ total protein.

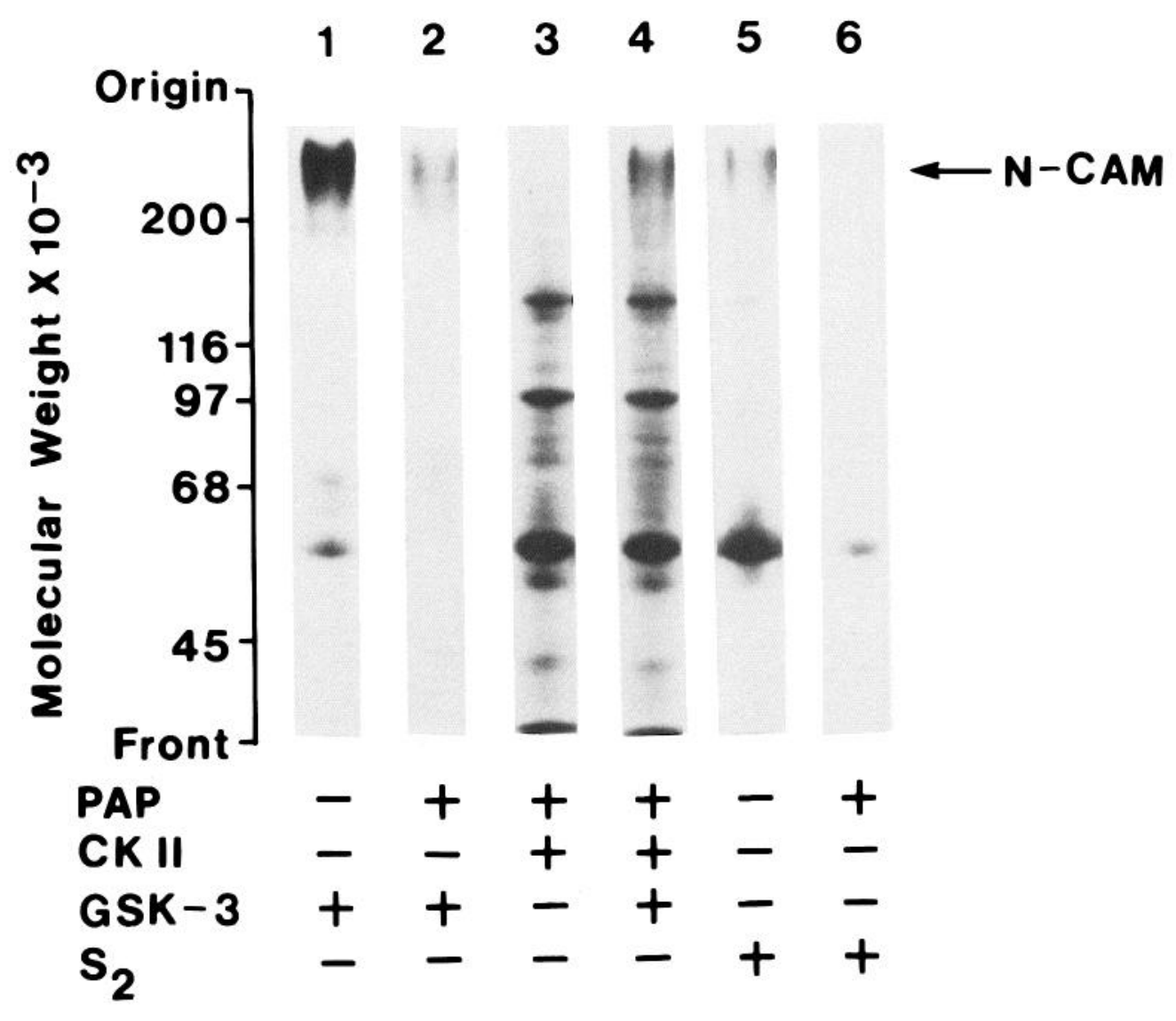

3 and 4 in the sd chain are phosphorylated only to a low level in culture, consistent with the observation that the sd polypeptide of purified N-CAM is a poor substrate for GSK-3.

The amino acid sequences of the CK I phosphorylation site in casein (glu-x-thr; Hathaway and Traugh, 1982) and the GSK-3 phosphorylation sites in glycogen synthase, $R_{n}$ and I-2 (thr-arg, thr-pro or thr-x-pro; Hemmings and Cohen, 1983; Aitken et al., 1984) are known. Assuming that the phosphorylation sites in N-CAM for GSK-3 and CK I are similar to the phosphorylation sites in the other known substrates, chicken N-CAM (Hemperly et al., 1986a) as well as mouse and rat N-CAM (Santoni et al., 1987; Small et al., 1987), contains several potential phosphorylation sites for both enzymes. N-CAM in brain membrane vesicles is phosphorylated only after solubilization with NP-40, and the ssd polypeptide is not a substrate for GSK-3 or CK I, consistent with previous proteolytic studies (Sorkin et al., 1984) suggesting that the phosphorylation sites are intracellular. In addition, the peptides phosphorylated by GSK-3 and $\mathrm{CK} I$ in both the ld and sd polypeptides are similar, and are probably in a shared region of the cytoplasmic domain. Since the phosphorylation of N-CAM on seryl residues appears to regulate the extent of phosphorylation by GSK-3 or CK I, the likely phosphorylated threonyl residues should be close to seryl residues. The region from amino acid 762 in the cytoplasmic domain of either chicken N-CAM polypeptide to the carboxyl terminus is unusually rich in threonyl residues and contains a number of potential phosphorylation sites for both enzymes. The same is true in mouse and rat. However, definitive localization of the phosphorylation sites in N-CAM will require amino acid sequence of the isolated phosphopeptides. 
Protein phosphorylation is a common mechanism through which diverse cellular responses are regulated, particularly in the nervous system (Greengard, 1987). Phosphorylation affects a variety of functions of many different cell surface proteins, including receptor affinity, clustering, and internalization, and interaction with the cytoskeleton or with cytoplasmic factors (Kelleher et al., 1984; May et al., 1984; Lin et al., 1986). In many cases, a single protein can be phosphorylated by different kinases, each activated by a discrete stimulus and having distinct effects on the function of the protein. We have found that $\mathrm{N}-\mathrm{CAM}$ is phosphorylated by several protein kinases, giving rise to relatively stable and to transient types of phosphorylation. In addition, the sd and Id polypeptides of N-CAM are differentially phosphorylated. The phosphorylation of N-CAM on each type of site (stable, transient, and Id polypeptide-specific) may have different effects on the function of the protein. Variations in the binding activity of N-CAM play a key role at sites of induction throughout development (Edelman, 1984, 1985). Phosphorylation of the cytoplasmic domains may affect binding activity, directly or indirectly, by altering protein distribution or mobility on the cell surface or by altering interactions with other cell-surface proteins or with cytoskeletal components. Since small increases in N-CAM concentration result in large increases in N-CAM-mediated adhesion (Hoffman and Edelman, 1983), the effect of phosphorylation on any of these properties would have important histogenetic conscquences.

Phosphorylation of N-CAM in vivo apparently occurs only when the molecule is in or close to the surface membrane (Lyles et al., 1984), suggesting that phosphorylation of these sites may be associated either with the maintenance of N-CAM at the cell membrane or with its interaction with other molecules in or near the membrane. The ld polypeptide has phosphorylation sites that are phosphorylated to different extents as well as phosphorylation sites that are distinct from those found in the sd polypeptide, suggesting that significant phosphorylation is unique to the ld polypeptide. This is of particular interest as the ld polypeptide is present only in neurons, and not in other adult tissues that express N-CAM such as skeletal muscle (Pollerberg et al., 1985; Murray et al., 1986) and has been reported to interact with brain spectrin and have a lower surface mobility than the sd polypeptide (Pollerberg et al., 1986). The differential phosphorylation of the ld polypeptide may be related to its specific interactions with molecules in the cytoskeleton or cytoplasm of neurons, while the phosphorylation of the sites that are common to the ld and sd polypeptides may regulate functions which are common to both polypeptides.

\section{References}

Aitken, A., C. F. B. Holmes, D. G. Campbell, T. J. Resink, P. Cohen, C. T. W. Leung, and D. H. Williams (1984) Amino acid sequence at the site on protein phosphatase inhibitor-2 phosphorylated by glycogen synthase kinase-3. Biochim. Biophys. Acta 790: 288-291.

Barbas, J. A., J.-C. Chaix, M. Steinmetz, and C. Goridis (1988) Differential splicing and alternative polyadenylation generates distinct NCAM transcripts and proteins in the mouse. EMBO J. 7:625-632.

Barthels, D., M.-J. Santoni, W. Wille, C. Ruppert, J.-C. Chaix, M.-R. Hirsch, J. C. Fontecilla-Camps, and C. Goridis (1987) Isolation and nucleotide sequence of mouse N-CAM cDNA that codes for $a \mathrm{M}_{r}$ 79,000 polypeptide without a membrane spanning region. EMBO J. 6: $907-914$.

Benovic, J. L., R. H. Strasser, M. G. Caron, and R. J. Lefkowitz (1986) $\beta$-adrenergic receptor kinase: Identification of a novel protein kinase that phosphorylates the agonist-occupied form of the receptor. Proc. Natl. Acad. Sci. USA 83: 2797-2801.

Chuong, C.-M., D. A. McClain, P. Streit, and G. M. Edelman (1982)
Neural cell adhesion molecules in rodent brains isolated by monoclonal antibodies with cross-species reactivity. Proc. Natl. Acad. Sci. USA 79: 4234-4238.

Cunningham, B. A., S. Hoffman, U. Rutishauser, J. J. Hemperly, and G. M. Edelman (1983) Molecular topography of N-CAM: Surface orientation and the location of sialic acid-rich and binding regions. Proc. Natl. Acad. Sci. USA 80: $3110-3120$.

Cunningham, B. A., J. J. Hemperly, B. A. Murray, E. A. Prediger, R. Brackenbury, and G. M. Edelman (1987) Structure of the neural cell adhesion molecule: Ig-like domains, cell surface modulation and alternative RNA splicing. Science 236: 799-806.

DePaoli-Roach, A. A. (1984) Synergistic phosphorylation and activation of ATP-Mg-dependent phosphoprotein phosphatase by $F_{\text {a }}$ GSK-3 and casein kinase II (PC0.7). J. Biol. Chem. 259: 12144-12152.

Detre, J. A., A. C. Nairn, D. W. Aswad, and P. Greengard (1984) Localization in mammalian brain of $\mathrm{G}$-sübstrate, a specific substrate for guanosine $3^{\prime}: 5^{\prime}$-cyclic monophosphate-dependent protein kinase. J. Neurosci. 4: 2843-2849.

Edelman, G. M. (1984) Modulation of cell adhesion during induction, histogenesis, and perinatal development of the nervous'system. Annu. Rev. Neurosci. 7: 339-377.

Edelman, G. M. (1985) Cell adhesion and the molecular processes of morphogenesis. Annu. Rev. Biochem. 54: 135-169.

Finne, J., U. Finne, H. Deagostini-Bazin, and C. Goridis (1983) Occurrence of $\alpha-2,8$ linked polysialosyl units in a neural cell adhesion molecule. Biochem. Biophys. Res. Commun. 112: 482-487.

Foulkes, J. G., and P. Cohen (1980) The regulation of glycogen metabolism: Purification and properties of protein phosphatase inhibitor-2 from rabbit skeletal muscle. Eur. J. Biochem. 105: 195-203.

Garber, B. B., and A. A. Moscona (1972) Reconstruction of brain tissue from cell suspensions. I. Aggregation patterns of cells dissociated from different regions of the developing brain. Dev. Biol. 27: 217-234.

Gennarini, G., G. Rougon, H. Deagostini-Bazin, M. Hirn, and C. Goridis (1984) Studies on the transmembrane disposition of the neural cell adhesion molecule N-CAM. Eur. J. Biochem. 142: 57-64.

Gennarini, G., M. R. Hirsch, H. T. He, M. Hirn, J. Finne, and C. Goridis (1986) Differential expression of mouse neural cell-adhesion molecule (N-CAM) mRNA species during brain development and in neural cell lines. J. Neurosci. 6: 1983-1990.

Grand, R. J. A., S. V. Perry, and R. A. Weeks (1979) Troponin C-like proteins (calmodulins) from mammalian smooth muscle and other tissues. Biochem. J. 177: 521-529.

Greengard, P. (1987) Neuronal phosphoproteins: Mediators of signal transduction. Mol. Neurobiol. 1: 81-119.

Hathaway, G. M., and J. A. Traugh (1982) Casein kinases-multipotential protein kinases. Curr. Top. Cell. Reg. 21: 101-127.

Hathaway, G. M., and J. A. Traugh (1983) Casein kinase II. Methods Enzymol. 99: 317-331.

Hathaway, G. M., P. T. Tuazon, and J. A. Traugh (1983) Casein kinase I. Methods Enzymol. 99: 308-317.

Hemmings, B. A., D. Yellowlees, J. C. Kernohan, and P. Cohen (1982a) Purification of glycogen synthase kinase- 3 from rabbit skeletal muscle: Copurification with the activating factor $\left(F_{a}\right)$ of the $(\mathrm{Mg}-\mathrm{ATP})$ dependent protein phosphatase. Eur. J. Biochem. 119: 443-451.

Hemmings, B. A., A. Aitken, P. Cohen, M. Rymond, and F. Hofmann (1982b) Phosphorylation of the type-II regulatory subunit of cyclic AMP-dependent protein kinase by glycogen synthase kinase 3 and glycogen synthase kinase 5. Eur. J. Biochem. 127: 473-481.

Hemmings, B. A., I. J. Resink, and P. Cohen (1982c) Reconstitution of a Mg-ATP-dependent protein phosphatase and its activation through a phosphorylation mechanism. FEBS Lett. 150: 319-324.

Hemmings, H. C., Jr., A. C. Nairn, D. W. Aswad, and P. Greengard (1984) DARPP-32, a dopamine and adenosine $3^{\prime}: 5^{\prime}$-monophosphate regulated phosphoprotein enriched in dopamine-innervated brain regions. II. Purification and characterization of the phosphoprotein from bovine caudate nucleus. J. Neurosci. 4: 99-110.

Hemperly, J. J., B. A. Murray, G. M. Edelman, and B. A. Cunningham (1986a) Sequence of a cDNA clone encoding the polysialic acid-rich and cytoplasmic domains of the neural cell adhesion molecule N-CAM. Proc. Natl. Acad. Sci. USA 83: 3037-3041.

Hemperly, J. J., G. M. Edelman, and B. A. Cunningham (1986b) cDNA clones of the neural cell adhesion molecule (N-CAM) lacking a membrane-spanning region consistent with evidence for membrane attachment via a phosphatidylinositol intermediate. Proc. Natl. Acad. Sci. USA 83: 9822-9826. 
Hoffman, S., and G. M. Edelman (1983) Kinetics of homophilic binding by $E$ and $A$ forms of the neural cell adhesion molecule. Proc. Natl. Acad. Sci. USA 80: 5762-5766.

Hoffman, S., B. C. Sorkin, P. C. White, R. Brackenbury, R. Mailhammer, U. Rutishauser, B. A. Cunningham, and G. M. Edelman (1982) Chemical characterization of a neural cell adhesion molecule purified from embryonic chicken brain membranes. J. Biol. Chem. 257:77207729 .

Ingebritsen, T. S., and P. Cohen (1983) Protein phosphatases: Properties and role in cellular regulation. Science 221: 331-338.

Ingebritsen, T. S., A. A. Stewart, and P. Cohen (1983) The protein phosphatases involved in cellular regulation: 6. Measurement of type- 1 and type- 2 protein phosphatases in extracts of mammalian tissues; an assessment of their physiological roles. Eur. J. Biochem. 132: 297-307.

Kaczmarek, L. K., K. R. Jennings, F. Strumwasser, A. C. Nairn, U. Walter, F. D. Wilson, and P. Greengard (1980) Microinjection of catalytic subunit of cyclic AMP-dependent protein kinase enhances calcium action potentials of bag cell neurons in cell culture. Proc. Natl. Acad. Sci. USA 77: 7487-7491.

Kelleher, D. J., J. E. Pessin, A. E. Ruoho, and G. L. Johnson (1984) Phorbol ester induces desensitization of adenylate cyclase and phosphorylation of the $\beta$-adrenergic receptor in turkey erythrocytes. Proc. Natl. Acad. Sci. USA 81: 4316-4320.

Kikkawa, U., Y. Takei, R. Minakuchi, S. Inohura, and Y. Nishizuka (1982) Calcium-activated, phospholipid-dependent protein kinase from rat brain. J. Biol. Chem. 257: 13341-13348.

Krebs, E. G., and J. A. Beavo (1979) Phosphorylation-dephosphorylation of cnzymes. Annu. Rev. Biochem. 48: 923-959.

Laemmli, U. K., and M. Favre (1973) Maturation of the head of bacteriophage T4. I. DNA packaging events. J. Mol. Biol. 80: 575599.

Lin, C. R., W. S. Chen, C. S. Lazar, C. D. Carpenter, G. N. Gill, R. M. Evans, and M. G. Rosenfeld (1986) Protein kinase C phosphorylation at thr 654 of the unoccupied EGF receptor and $\mathrm{EGF}$ binding regulate functional receptor loss by independent mechanisms. Cell 44: 839-848.

Lyles, J. M., D. Linnemann, and E. Bock (1984) Biosynthesis of the D2-cell adhesion molecule: Post-translational modifications, intracellular transport, and developmental changes. J. Cell Biol. 99: 20822091.

May, W. S., S. Jacobs, and P. Cuatrecasas (1984) Association of phorbol cstcr-induccd hyperphosphorylation and reversible regulation of the transferrin membrane receptors in HL60 cells. Proc. Natl. Acad. Sci. USA 81: 2016-2020.

McGuinness, T. L., Y.-Y. Lai, and P. Greengard (1985) $\mathrm{Ca}^{21 / \mathrm{cal}-}$ modulin-dependent protein kinase II: Isozymic forms from rat forebrain and cerebellum. J. Biol. Chem. 260: 1696-1704.

Murray, B. A., J. J. Hemperly, E. A. Prediger, G. M. Edelman, and B. A. Cunningham (1986a) Alternatively spliced mRNAs code for different polypeptide chains of the chicken neural cell adhesion molecule (N-CAM). J. Cell Biol. 102: 189-193.

Murray, B. A., G. C. Owens, E. A. Prediger, K. L. Crossin, B. A. Cunningham, and G. M. Edelman (1986b) Cell surface modulation of the neural cell adhesion molecule resulting from alternative mRNA splicing in a tissue specific developmental sequence. J. Cell Biol. 103: 1431-1439.

Nairn, A. C., and P. Greengard (1987) Purification and characterization of $\mathrm{Ca}^{2+} /$ calmodulin-dependent protein kinase I from bovine brain. J. Biol. Chem. 262: 7273-7281.
Nairn, A. C., B. Bhagat, and H. C. Palfrey (1985) Identification of calmodulin-dependent protein kinase III and its major $\mathbf{M}_{r} 100,000$ substrate in mammalian tissues. Proc. Natl. Acad. Sci. USA 82: 7939 7943.

Nestler, E. J., and P. Greengard (1984) Protein Phosphorylation in the Nervous System, Wiley, New York.

Peterson, G. (1977) A simplification of the protein assay method of Lowry, et al. which is more generally applicable. Anal. Biochem. 83: 346-356.

Picton, C., J. Woodgett, B. A. Hemmings, and P. Cohen (1982) Multisite phosphorylation of glycogen synthase from rabbit skeletal muscle: Phosphorylation of site 5 by glycogen synthase kinase- 5 (casein kinase-II) is a prerequisite for phosphorylation of site 3 by glycogen synthase kinase-3. FEBS Lett. 150: 191-196.

Pollerberg, E. G., R. Sadoul, C. Goridis, and M. Schachner (1985) Selective expression of the $180-\mathrm{kD}$ component of the neural cell adhesion molecule N-CAM during development. J. Cell Biol. 101: 19211929.

Pollerberg, E. G., M. Schachner, and J. Davoust (1986) Differentiation state-dependent surface mobilities of two forms of the neural cell adhesion molecule. Nature 324: 462-465.

Resink, T. J., B. A. Hemmings, H. Y. L. Tung, and P. Cohen (1983) Characterisation of a reconstituted Mg-ATP-dependent protein phosphatase. Eur. J. Biochem. 133: 455-461.

Rylatt, D. B., A. Aitken, T. Bilham, G. D. Condon, N. Embi, and P. Cohen (1980) Glycogen synthase from rabbit skeletal muscle. Eur. J. Biochem. 107: 529-537.

Santoni, M. J., D. Barthels, J.-A. Barbas, M. Steinmetz, C. Goridis, and W. Wille (1987) Analysis of cDNA clones that code for the transmembrane forms of the mouse neural cell adhesion molecule (NCAM) and are generated by alternative RNA splicing. Nucleic Acid Res. 15 . $8621-8641$.

Small, S. J., G. E. Shull, M.-J. Santoni, and R. Akeson (1987) Identification of a cDNA clone that contains the complete coding sequence for a 140-kDa rat NCAM polypeptide. J. Cell Biol. 105: 2335-2345.

Sorkin, B. C., S. Hoffman, G. M. Edelman, and B. A. Cunningham (1984) Sulfation and phosphorylation of the Neural Cell Adhesion Molecule, N-CAM. Science 225: 1476-1478.

Thiery, J.-P., J.-L. Duband, U. Rutishauser, and G. M. Edelman (1982) Cell adhesion molecules in early chicken embryogenesis. Proc. Natl. Acad. Sci. USA 79: 6737-6741.

Ueda, T., and P. Greengard (1977) Adenosine $3^{\prime}: 5^{\prime}$-monophosphateregulated phosphoprotein system of neuronal membranes. I. Solubilization, purification and some properties of an endogenous phosphoprotein. J. Biol. Chem. 252: 5155-5163.

Walaas, S. I., A. C. Nairn, and P. Greengard (1983) Regional distribution of calcium- and cyclic adenosine $3^{\prime}: 5^{\prime}$-monophosphate-regulated protein phosphorylation systems in mammalian brain. I. Particulate systems. J. Neurosci. 3: 291-301.

Walter, U., P. Miller, F. Wilson, D. Menkes, and P. Greengard (1980) Immunological distinction between guanosine $3^{\prime}: 5^{\prime}$-monophosphatedependent and adenosine $3^{\prime}: 5^{\prime}$-monophosphate-dependent protein kinases. J. Biol. Chem. 255: 3757-3762.

Woodgett, J. R., and P. Cohen (1984) Multisite phosphorylation of glycogen synthase: Molecular basis for the substrate specificity of glycogen synthase kinase- 3 and casein kinase II (glycogen synthase kinase-5). Biochim. Biophys. Acta 788: 339-347. 